\title{
FORECASTING QUARTERLY GERMAN GDP AT MONTHLY INTERVALS USING MONTHLY IFO BUSINESS CONDITIONS DATA
}

\author{
STEFAN MitTNIK \\ PETER ZADROZNY
}

\author{
CESIFO WORKING PAPER NO. 1203 \\ CATEGORY 5: FisCAL POLICY, MACROECONOMICS AND GROWTH \\ MAY 2004 \\ Presented at CESifo Conference “ACAdemic Use of Ifo Survey DatA" \\ DECEMBER 2003
}

\footnotetext{
An electronic version of the paper may be downloaded

- from the SSRN website: Www.SSRN.com

- from the CESifo website: www.CESifo.de
} 


\title{
FORECASTING QUARTERLY GERMAN GDP AT MONTHLY INTERVALS USING MONTHLY IFO BUSINESS CONDITIONS DATA
}

\begin{abstract}
The paper illustrates and evaluates a Kalman filtering method for forecasting German real GDP at monthly intervals. German real GDP is produced at quarterly intervals but analysts and decision makers often want monthly GDP forecasts. Quarterly GDP could be regressed on monthly indicators, which would pick up monthly feedbacks from the indicators to GDP, but would not pick up implicit monthly feedbacks from GDP onto itself or the indicators. An efficient forecasting model which aims to incorporate all significant correlations in monthlyquarterly data should include all significant monthly feedbacks. We do this with estimated VAR(2) models of quarterly GDP and up to three monthly indicator variables, estimated using a Kalman-filtering-based maximum-likelihood estimation method. Following the method, we estimate monthly and quarterly VAR(2) models of quarterly GDP, monthly industrial production, and monthly, current and expected, business conditions. The business conditions variables are produced by the Ifo Institute from its own surveys. We use early insample data to estimate models and later out-of-sample data to produce and evaluate forecasts. The monthly maximum-likelihood-estimated models produce monthly GDP forecasts. The Kalman filter is used to compute the likelihood in estimation and to produce forecasts. Generally, the monthly German GDP forecasts from 3 to 24 months ahead are competitive with quarterly German GDP forecasts for the same time-span ahead, produced using the same method and the same data in purely quarterly form. However, the present mixed-frequency method produces monthly GDP forecasts for the first two months of a quarter ahead which are more accurate than one-quarter-ahead GDP forecasts based on the purely-quarterly data. Moreover, quarterly models based on purely-quarterly data generally cannot be transformed into monthly models which produce equally accurate intra-quarterly monthly forecasts.
\end{abstract}

JEL classification: E37, C32.

Keywords: mixed-frequency data, VAR models, maximum-likelihood estimation, Kalman filter.

\author{
Stefan Mittnik \\ University of Munich \\ Akademiestr. 1 \\ 80799 Munich \\ Germany \\ finmetrics@stat.uni-muenchen.de
}

\author{
Peter Zadrozny \\ Bureau of Labor Statistics \\ 2 Massachusetts Ave., NE \\ Washington, DC 20212 \\ USA \\ zadrozny_p@bls.gov
}

The opinions expressed in the paper are the authors' and do not reflect any official positions of the Bureau of Labor Statistics. 


\section{Introduction}

This paper illustrates and evaluates a Kalman-filtering method for forecasting German real GDP at monthly intervals. Like U.S. real GDP, German real GDP is produced and publicly released at quarterly intervals, although both U.S. and German economic analysts and business decision makers often want monthly GDP forecasts. Quarterly GDP could be regressed on monthly indicators organized quarterly. Thus, one could: (i) organize all observations on variables at quarterly intervals, with GDP automatically being quarterly and monthly indicators being made quarterly as first-, second--, and third-month quarterly observations; (ii) regress quarterly GDP on the monthly indicators organized quarterly; and, (iii) compute monthly GDP forecasts as the estimated regression evaluated at particular values of the monthly indicators. This description is purposely simple to illustrate the general point that a regression can pick up feedbacks of monthly variables onto quarterly variables but it cannot pick up implicit intra-quarterly monthly feedbacks from quarterly to monthly variables. To avoid this problem, we use a Kalman-filtering method developed by Zadrozny [10] for any number of variables observed at any mixture of frequencies and illustrated in a similar context of forecasting quarterly U.S. real GNP at monthly intervals using a monthly indicator. The method can account for any possible feedbacks, from any variable at any frequency to any other variable at the same or other frequency. The method involves estimating a multivariate time-series model of all variables being considered. The model operates at the highest observed frequency, monthly in this case, and, thus, produces forecasts of any variable at monthly intervals, regardless of the interval at which the variable is observed. Here, data are set up at the highest monthly frequency so that unobserved intra-quarterly monthly values of quarterly GDP are marked as missing. Maximum likelihood estimation (MLE) is used to estimate $\operatorname{VAR}(2)$ models. The Kalman filter is used in two ways. First, the Kalman filter is used to compute the likelihood function, under Gaussian or normality assumptions, which is maximized with respect to unknown model parameters. Second, given an estimated model, the Kalman filter is used to produce forecasts of variables, at the higher monthly frequency at which the model operates, any number of months ahead. In both cases, the Kalman filter is applied in a "missing data" form in order to "properly skip over" missing values. Details of these computations are discussed by Zadrozny [10]. The method allows models as general as vector autoregressive movingaverage (VARMA) models, although previous and current experience indicates that purely VAR models often suffice for forecasting a variable with the help of other variables, when no restrictions on coefficients, indicated by statistical analysis or economic reasoning, are imposed on the forecasting model.

\section{Description of Data}

The data, obtained from the Ifo Institute in Munich, Germany, comprise quarterly German real GDP and three monthly indicators of the German economy: German real industrial production (PRD), current German real business conditions (CUR) and expected (6 months in the future) German real business 
conditions (EXP). The business conditions variables are produced by the Ifo Institute from its own surveys of German business firms. The monthly data cover January 1970 to December 2003 and the quarterly GDP data cover the same period, quarter 11970 to quarter 42003.

The four variables and their filtered values are displayed in figures 1-9. Figures 1-3 are monthly time plots and figures $4-9$ are quarterly time plots. In the monthly graphs, the monthly variables are displayed as continuous lines, with no missing values, and quarterly GDP is displayed as a broken or dashed line, with missing intra-quarterly monthly values. Because each quarter's GDP is fully assigned to the third month of the quarter, GDP is treated as unobserved or missing in the first two intra-quarterly months of a quarter.

There are no missing values after the data are aggregated into quarterly form, so all displayed lines in the quarterly graphs are continuous. GDP is automatically in quarterly form. There are two ways, called "stock" and "flow," for aggregating monthly values to quarterly values. "Stock" means monthly values are skip sampled in the third month of each quarter, so that the value in the third month of a quarter becomes the quarterly value and the values in the first two months of the quarter are discarded. "Flow" means monthly values are aggregated into quarterly form by averaging the monthly values in a quarter. Also, monthly PRD is detrended and deseasonalized in two possible ways, called "AD filtered" and "AD/AMA filtered," to be discussed. Thus, the four ways considered for converting monthly-quarterly data to purelyquarterly data are called stock-AD-filtered, stock-AD/AMA-filtered, flowAD-filtered, and flow- AD/AMA-filtered.

The variables are graphed in original and filtered forms. Henceforth, we use subscript $t$ to denote months, e.g., $\mathrm{PRD}_{t}$ means $\mathrm{PRD}$ in month $t$, and for now let $\mathrm{L}^{k}$ denote the monthly lag operator applied $k$ times in succession to a monthly variable, e.g., $\mathrm{L}^{12} \mathrm{PRD}_{t}=\mathrm{PRD}_{t-12}$. We know that the annual differencing operator, defined for monthly time intervals as $\mathrm{AD}(\mathrm{L})=1-\mathrm{L}^{12}$, is the product of a single monthly difference, $\mathrm{MD}(\mathrm{L})=1-\mathrm{L}$, times a single annual sum, $\mathrm{AS}(\mathrm{L})=1+\mathrm{L}+\ldots+\mathrm{L}^{11}$, or $\mathrm{AD}(\mathrm{L})=\mathrm{MD}(\mathrm{L}) \mathrm{AS}(\mathrm{L})$. Frequency analysis shows that multiplying a variable by $\mathrm{MD}(\mathrm{L})$ eliminates its linear deterministic (polynomial) and linear stochastic (unit-root autoregressive) trends and multiplying the variable by $\mathrm{AS}(\mathrm{L})$ eliminates its deterministic (harmonic) seasonality, although a variable can have additional stochastic seasonality which cannot be removed by $\mathrm{AS}(\mathrm{L})$. This appears to be the case with $\mathrm{PRD}_{t}$, which is discussed below.

Figure 1 displays the four variables in original monthly form. We see that $\mathrm{GDP}_{t}$ follows an upward trend with additional, relatively small, seasonal variations about the trend. $\mathrm{PRD}_{t}$ also follows an upward trend, with relatively larger seasonal variations about the trend, plus more easily seen cyclical variations. $\mathrm{CUR}_{t}$ and $\mathrm{EXP}_{t}$ both display no apparent trends or seasonality, only cyclical variations. Because in original form the variables are compatible only as $\mathrm{GDP}_{t}$ with $\mathrm{PRD}_{t}$ and $\mathrm{CUR}_{t}$ with $\mathrm{EXP}_{t}$, there is little hope of obtaining MLE of a VAR model of the four variables in original form, namely $\mathrm{GDP}_{t}$, $\mathrm{PRD}_{t}, \mathrm{CUR}_{t}$, and $\mathrm{EXP}_{t}$. Therefore, to obtain MLE of a VAR model of the four variables, we first linearly filtered $\mathrm{GDP}_{t}$ and $\mathrm{PRD}_{t}$ to eliminate their 
trends and seasonality, so that the resulting four variables display only cyclical variations and are compatible.

As seen in the figures, the main difference between monthly data versus quarterly data and quarterly-stock data versus quarterly-flow data is smoothness versus noisiness, where "noisiness" means unpredictable high-frequency random variation and "smoothness" means absence of noisiness. As expected, monthly data are noisier than quarterly data and quarterly-stock data are noisier than quarterly-flow data. We expect smoother data to produce better GDP forecasts. Summary table 8 shows that smoother quarterly data produce better long-term GDP forecasts than noisier monthly data, but that choosing stocks instead of flows or $\mathrm{AD}$ instead of $\mathrm{AD} / \mathrm{AMA}$ filtering has insignificant effect on GDP forecast accuracy.

\section{Transformation of Data}

We filtered $\mathrm{GDP}_{t}$ and $\mathrm{PRD}_{t}$, respectively, using the single quarterly difference, $\mathrm{QD}(\mathrm{L})=1-\mathrm{L}^{3}$, and $\mathrm{MD}(\mathrm{L})$, graphed the results, and visually determined that $\mathrm{QD}(\mathrm{L})$ and $\mathrm{MD}(\mathrm{L})$ remove trends from $\mathrm{GDP}_{t}$ and $\mathrm{PRD}_{t}$. Because $\mathrm{GDP}_{t}$ is observed only in the third month of a quarter, the shortest time interval over which it can be differenced to remove trend is the quarter. Then, in effect, we filtered $\mathrm{QD}(\mathrm{L}) \mathrm{GDP}_{t}$ and $\mathrm{MD}(\mathrm{L}) \mathrm{PRD}_{t}$ using $\mathrm{AS}(\mathrm{L})$. Actually, we restarted the filtering and directly annually differenced $\mathrm{GDP}_{t}$ and $\mathrm{PRD}_{t}$ using $\mathrm{AD}(\mathrm{L})$, which amounts to the same operation. Then, we graphed the results and visually determined that $\mathrm{AD}(\mathrm{L})$ removes trends and seasonality from $\mathrm{GDP}_{t}$ and $\mathrm{PRD}_{t}$. Although we do not display the intermediate $\mathrm{QD}(\mathrm{L})$ - and $\mathrm{MD}(\mathrm{L})$-filtered results, figure 2 displays the final monthly AD-filtered $\mathrm{GDP}_{t}$ and $\mathrm{PRD}_{t}$, denoted $\mathrm{AD}\left(\mathrm{GDP}_{t}\right)$ and $\mathrm{AD}\left(\mathrm{PRD}_{t}\right)$, and the original unfiltered $\mathrm{CUR}_{t}$ and $\mathrm{EXP}_{t}$. Because $\mathrm{AD}\left(\mathrm{GDP}_{t}\right), \mathrm{AD}\left(\mathrm{PRD}_{t}\right), \mathrm{CUR}_{t}$, and $\mathrm{EXP}_{t}$ display only cyclical variations, in this mixed form the four variables are compatible and suitable for estimating a VAR model.

AD filtered means $\mathrm{GDP}_{t}$ and $\mathrm{PRD}_{t}$ are filtered using only $\mathrm{AD}(\mathrm{L})$ and $\mathrm{CUR}_{t}$ and $\mathrm{EXP}_{t}$ are unfiltered. Initial model estimation resulted in $\mathrm{PRD}_{t}$ residuals with a significantly negative autocorrelation coefficient at the annual lag, indicating $\mathrm{AD}(\mathrm{L})$ does not remove all seasonality from $\mathrm{PRD}_{t}$. Therefore, we extended $\mathrm{AD}(\mathrm{L})$ to an "airline model," with an additional estimated annual (seasonal) first-order moving-average term, to remove any remaining significant stochastic seasonality from $\mathrm{PRD}_{t}$. We denote airline-model filtered $\mathrm{PRD}_{t}$ by $\mathrm{AD} / \mathrm{AMA}\left(\mathrm{PRD}_{t}\right)$, where AMA refers to annual moving average. The term "airline model" comes from Box and Jenkins [1] and is often the "default" model in a search for the best ARIMA seasonal-adjustment model.

We extended monthly $\mathrm{AD}\left(\mathrm{PRD}_{t}\right)$ to monthly $\mathrm{AD} / \mathrm{AMA}\left(\mathrm{PRD}_{t}\right)$ as follows. We supposed $\mathrm{AD}\left(\mathrm{PRD}_{t}\right)$ is generated by the seasonal-adjustment model $\mathrm{AD}\left(\mathrm{PRD}_{t}\right)=\left(1-\phi_{1} \mathrm{~L}-\phi_{2} \mathrm{~L}^{2}-\phi_{3} \mathrm{~L}^{3}\right)^{-1}\left(1+\theta \mathrm{L}^{12}\right) \varepsilon_{t}$, where the nonseasonal $\operatorname{AR}(3)$ component $\left(1-\phi_{1} \mathrm{~L}-\phi_{2} \mathrm{~L}^{2}-\phi_{3} \mathrm{~L}^{3}\right)^{-1}$ accounts for cyclicality, the seasonal $\mathrm{MA}(1)$ component $1+\theta \mathrm{L}^{12}$ accounts for stochastic seasonality, and $\varepsilon_{t}$ is a white-noise disturbance distributed $\operatorname{NIID}\left(0, \sigma_{\varepsilon}^{2}\right)$. Note 
that both the univariate seasonal-adjustment models and the multivariate VAR models for GDP forecasting were estimated using mean-adjusted and standardized data (divided by standard deviation after mean adjustment). The data and the estimated $\operatorname{AR}(3)$ component are stationary, which means that $1-\phi_{1} \lambda-\phi_{2} \lambda^{2}-\phi_{3} \lambda^{3}=0$ implies $|\lambda|>1$, and the seasonal MA(1) is estimated as invertible, which means that $|\theta|<1$. $\mathrm{AD} / \mathrm{AMA}\left(\mathrm{PRD}_{t}\right)$ is defined as $\left(1+\theta \mathrm{L}^{12}\right)^{-1} \mathrm{AD}\left(\mathrm{PRD}_{t}\right)$ and is approximated by four terms: $\mathrm{AD} / \mathrm{AMA}\left(\mathrm{PRD}_{t}\right)=$ missing, for $t=1, \ldots, 48$, and $\mathrm{AD} / \mathrm{AMA}\left(\mathrm{PRD}_{t}\right)=$ $\mathrm{PRD}_{t}-(1+\hat{\theta}) \mathrm{PRD}_{t-12}+\hat{\theta}(1+\hat{\theta}) \mathrm{PRD}_{t-24}-\hat{\theta}^{2}(1+\hat{\theta}) \mathrm{PRD}_{t-36}+\hat{\theta}^{3}(1+\hat{\theta})$ $\mathrm{PRD}_{t-48}$, for $t=49, \ldots, 408$, where monthly $\hat{\theta}=-.5033$ is estimated jointly with the AR parameters, using MLE.

Similarly, we extended quarterly $\mathrm{AD}\left(\mathrm{PRD}_{s}\right)$ to quarterly $\mathrm{AD} / \mathrm{AMA}\left(\mathrm{PRD}_{s}\right)$, using the analogous model $\mathrm{AD}\left(\mathrm{PRD}_{s}\right)=\left(1-\phi_{1} \mathrm{~L}-\phi_{2} \mathrm{~L}^{2}-\phi_{3} \mathrm{~L}^{3}\right)^{-1}\left(1+\theta \mathrm{L}^{4}\right)$ $\varepsilon_{s}$, where subscript $s$ denotes quarters and $\mathrm{L}$ now denotes the quarterly lag operator. $\mathrm{AD} / \mathrm{AMA}\left(\mathrm{PRD}_{s}\right)$ is defined as $\left(1+\theta \mathrm{L}^{4}\right)^{-1} \mathrm{AD}\left(\mathrm{PRD}_{s}\right)$ and is approximated by four terms: $\mathrm{AD} / \mathrm{AMA}\left(\mathrm{PRD}_{s}\right)=$ missing, for $s=1, \ldots, 16$, and $\mathrm{AD} / \mathrm{AMA}\left(\mathrm{PRD}_{s}\right)=\mathrm{PRD}_{s}-(1+\hat{\theta}) \mathrm{PRD}_{s-4}+\hat{\theta}(1+\hat{\theta}) \mathrm{PRD}_{s-8}-\hat{\theta}^{2}$ $(1+\hat{\theta}) \mathrm{PRD}_{s-12}+\hat{\theta}^{3}(1+\hat{\theta}) \mathrm{PRD}_{s-16}$, for $s=17, \ldots, 136$, where $\hat{\theta}=-.6769$ using quarterly stock data and $\hat{\theta}=-.5041$ using quarterly flow data.

Both monthly and quarterly $\mathrm{AD}$-filtered data comprise $\mathrm{AD}(\mathrm{GDP}), \mathrm{AD}$ (PRD), CUR, and EXP and monthly and quarterly AD/AMA-filtered data comprise $\mathrm{AD}(\mathrm{GDP}), \mathrm{AD} / \mathrm{AMA}(\mathrm{PRD}), \mathrm{CUR}$, and EXP. Because AD/AMA (PRD) is smoother than $\mathrm{AD}(\mathrm{PRD})$, as seen for example in the quarterly figures 4-9, we might expect more accurate GDP forecasts using AD/AMA(PRD). But, because this was not always the case, we did not further extend the AD/AMA model and filter to a more detailed seasonal-adjustment model and filter (cf., Flaig [4]). Thus, present forecasting results indicate some seasonal adjustment is necessary to put all variables in compatible cyclical form in order to estimate a forecasting model, but table 8 shows that a more thorough seasonal adjustment does not necessarily improve short- or long-term forecasts. Of course, a government statistical agency responsible for producing seasonally-adjusted data is obliged to produce thoroughly adjusted data, whatever the consequences in subsequent applications.

Because log-form data are often more homogeneous (have more constant variances or homoskedasticity), hence, are often easier to fit, we also considered $\log$-form data. Because non-missing original values of $\mathrm{GDP}_{t}$ and $\mathrm{PRD}_{t}$ values are positive, these variables were transformed directly to natural logs. However, because values of $\mathrm{CUR}_{t}$ and $\mathrm{EXP}_{t}$ are negative, zero, or positive fractions, they were indirectly transformed into logs as follows. For example, consider $\mathrm{CUR}_{t}$ and suppose $d_{t}, u_{t}$, and $i_{t}$ denote the fractions of survey respondents who, respectively, said current business conditions declined, are unchanged, or improved. Then, $\mathrm{CUR}_{t}=i_{t}-d_{t}$, such that $u_{t}$ is ignored. However, because $d_{t}+u_{t}+i_{t}=1$ and assuming $u_{t}=0$, $i_{t} / d_{t}=\left(1+\mathrm{CUR}_{t}\right) /\left(1-\mathrm{CUR}_{t}\right)>0$, so that $\ln \left[\left(1+\mathrm{CUR}_{t}\right) /\left(1-\mathrm{CUR}_{t}\right)\right]$ is well defined and can be considered the "log" of CUR ${ }_{t}$ and similarly for $\mathrm{EXP}_{t}$. 
Thus, we computed $\mathrm{AD}$-filtered $\ln \left(\mathrm{GDP}_{t}\right)$ and $\ln \left(\mathrm{PRD}_{t}\right)$, as in the unlogged cases, and unfiltered $\ln \left(\mathrm{CUR}_{t}\right)$ and $\ln \left(\mathrm{EXP}_{t}\right)$. Resulting graphs of monthly, original and filtered, log-form data were very close to those in figures 1-3. Also, monthly model estimates were very similar, regardless whether the data were log transformed or not. Thus, we did not conduct further analysis with the $\log$-form data.

\section{Estimation of VAR Models}

In principle, we searched for the best combination of monthly indicators for forecasting GDP (we now denote filtered GDP and PRD more simply as "GDP" and "PRD," without AD or AD/AMA). In practice, we restricted the search to three of seven possibilities: models of GDP, PRD, CUR, and EXP; models of GDP, PRD, and CUR; and, models of GDP and PRD. First, we dropped EXP because it is considered the less informative Ifo variable and is somewhat redundant statistically, given CUR. Then, we dropped CUR to see what difference using any Ifo variables makes in forecasting GDP. Finally, we kept PRD because it is often the first choice of a monthly indicator when forecasting GDP.

We aimed for "adequate" estimated VAR models, by which we mean the following. As usual, our ideal was models with minimum numbers of parameters and zero-mean, constant-variance, and independently-distributed residuals. For each of the three variable sets, we estimated unrestricted $\operatorname{VAR}(1)$ models, whose residuals showed significant serial correlations, and, then, estimated unrestricted $\operatorname{VAR}(2)$ models, whose residuals showed mostly insignificant correlations except for a few higher-lag correlations which could not be accounted for with lower-order VAR models. Thus, we accepted estimated $\operatorname{VAR}(2)$ models as adequately fitting the three sets of variables. In reaching this conclusion, we inspected graphs of residual own- and cross-serial correlations, evaluated $p$ values of Ljung-Box Q statistics [6] and evaluated information criteria. Although Ljung-Box Q statistics were developed to test for significant residual own-serial correlations, we also used them to test for significant residual cross-serial correlations. We did not test for significance of individual estimated parameters or remove any.

For the eighteen final estimated $\operatorname{VAR}(2)$ models, in table 1 we report only $\mathrm{R}_{e}^{2}$ (the usual $\mathrm{R}$-squared called "estimation $\mathrm{R}$ squared," which is distinguished in section 5 from $\mathrm{R}_{f, h}^{2}$, called "forecasting $\mathrm{R}$ squared"). We do not report estimated parameters because, as usual in VAR models, they are very imprecise and, thus, provide little reliable information about feedbacks among variables. We also computed implied estimated AR characteristic roots which were all expectedly and firmly stationary. Although $\mathrm{R}_{e}^{2}$ does not account for degrees of freedom used in estimation, only pertains to individual variables, and does not pertain to complete estimated models, nevertheless, higher values of $\mathrm{R}_{e}^{2}$ are generally associated with more accurate GDP forecasts as seen by comparing table 1 with tables 2-8. We used "in sample" data from January 1970 to December 1993 to estimate models and "out of sample" data from January 1994 to December 2003 to produce and evaluate GDP forecasts. 
We implemented the MLE using a FORTRAN 77 program, compiled the program using the Lahey-Fujitsu FORTRAN 95 complier version 5.6, and executed the program on a personal computer with a Pentium 4 central processor, running at about 2 gigahertz speed and controlled by the Windows XP operating system. Using a $10^{-8}$ convergence criterion, estimating the largest models, with 4 variables and 42 parameters, took about 4000 iterations or less than 20 minutes from start to finish. We started all iterations by setting parameter values to .01. If iterations stalled (reached a point in parameter space where the likelihood function appeared flat in all directions so that no further moves were made, even though convergence was not achieved), we restarted them at the last parameter values. Sometimes we restarted the iterations several times before achieving convergence. Thus, the MLE was not automatic and needed intervention.

\section{Evaluation of GDP Forecasts}

For the GDP forecasts, we define normalized root mean squared forecast error for $h$-period-ahead forecasts as $\mathrm{NRMSFE}_{h}=\sqrt{\left(\sum_{t=1}^{T} e_{t / h-h}^{2}\right) / T} \div$ out-ofsample standard deviation of GDP, where $e_{t \mid t-h}=\mathrm{GDP}_{t}-\mathrm{GDP}_{t \mid t-h}=$ error of forecasting $\mathrm{GDP}_{t}$ in period $t-h$, for out-of-sample periods $t=1, \ldots T$, missing values of $e_{t \mid t-h}$ are dropped from the summation, and $T$ is reduced correspondingly. For every variable, we define estimation $\mathrm{R}$-squared as the usual $\mathrm{R}_{e}^{2}=1$ - in-sample variance of a variable's residual in an estimated model $\div$ in-sample variance of the variable and define forecasting $\mathrm{R}$-squared as $R_{f, h}^{2}=1-\mathrm{NRMSFE}_{h}^{2}$, for $h \geq 1$. First, generally, $\mathrm{R}_{f, h}^{2} \leq \mathrm{R}_{e}^{2}$ and, equivalently, $\mathrm{NRMSFE}_{h} \geq \sqrt{1-\mathrm{R}_{e}^{2}}$, for $h \geq 1$. $\mathrm{R}_{f, h}^{2} \cong \mathrm{R}_{e}^{2}$ and $\mathrm{NRMSFE}_{h} \cong \sqrt{1-\mathrm{R}_{e}^{2}}$, for $h \geq 1$, suggest that the data generating process has changed not at all or insignificantly between the in- and out-ofsample periods, so that out-of-sample forecasts should be maximally accurate. Alternately, $\mathrm{R}_{f, h}^{2}<<\mathrm{R}_{e}^{2}$ and $\mathrm{NRMSFE}_{h}>>\sqrt{1-\mathrm{R}_{e}^{2}}$, for $h \geq 1$, suggest that the data generating process has changed significantly between inand out-of-sample periods, where $<<$ and $>>$ denote "much less than" and "much greater than". Second, an efficient forecast, which fully exploits available information, is orthogonal to its forecast error, so that $\mathrm{R}_{f, h}^{2}>0$ and $\mathrm{NRMSFE}_{h}<1$, for $h \geq 1$. Because the last conditions are necessary, but not sufficient, for efficiency, $\mathrm{R}_{f, h}^{2} \leq 0$ and $\mathrm{NRMSFE}_{h} \geq 1$, for $h \geq 1$, imply that a forecast is inefficient, but $\mathrm{R}_{f, h}^{2}>0$ and $\mathrm{NRMSFE}_{h}<1$, for $h \geq 1$, do not imply that the forecast is efficient.

Tables $1-7$ show that $\mathrm{R}_{e}^{2}$ is significantly greater than any $\mathrm{R}_{f, h}^{2}$, which suggests that the data generating process of the German economy changed significantly after 1993. This is what we expect as a result of the immediate political and evolving economic unification of Germany in 1990. We produced nonrecursive forecasts based on fixed models estimated using fixed in-sample data. Recursive forecasts based on models reestimated using recursively updated 
in-sample data should reduce the differences between $\mathrm{R}_{e}^{2}$ and $\mathrm{R}_{f, h}^{2}$. Table 8 shows that monthly-long-term GDP forecasts are inefficient, certainly relative to quarterly-long-term GDP forecasts. Thus, we disregard these forecasts and further evaluate only the remaining three cases.

We can compare forecasts "internally" by comparing in-sample $\mathrm{R}_{e}^{2}$ and out-of-sample $\mathrm{R}_{f, h}^{2}$ based on the same estimated model of interest, or, we can compare forecasts "externally" by comparing out-of-sample $\mathrm{R}_{f, h}^{2}$ and $\mathrm{NRMSFE}_{h}$ for the model of interest and competing "external" models. External comparisons are costly to the extent that competing models must be developed, although both comparisons should be made. For simplicity, we focus on internal comparisons and report external comparisons only in terms of Theil U statistics for essentially costless "naive" forecasts. By definition, Theil $\mathrm{U}=\mathrm{NRMSFE}_{h}$ of the forecast of interest $\div \mathrm{NRMSFE}_{h}$ of the naive forecast, where the naive forecast is the last observed value of the variable of interest at least $h$ periods ago Doan [3]. A Theil $\mathrm{U}$ value $<1$ implies that the forecasts of interest are better than the naive forecasts. As hoped, this occurs in almost all cases in tables $2-7$. Although we focus on $\mathrm{NRMSFE}_{h}$ and $\mathrm{R}_{f, h}^{2}$, conclusions based on Theil $\mathrm{U}$ would be the same.

We used the following test to determine whether using the Ifo variables, CUR and EXP, results in better monthly or quarterly GDP forecasts. In the undiscarded, monthly-short-term and quarterly, cases in table 8, we let $\rho$ denote the total number of variables in the $50 \%$-best-forecasting models divided by the total number of variables in the $50 \%$-worst-forecasting models. Thus, .636 $\leq \rho \leq 1.571$; because using 2 , 3 , or 4 variables means using 0,1 , or 2 Ifo variables, higher values of $\rho$ imply that using Ifo variables produces better GDP forecasts; and, if $\rho$ is uniformly distributed, its bottom quartile spans $[.636, .870]$, its middle quartiles span $[.870,1.338]$, and its top quartile spans $[1.338,1.571]$. Thus, if $\rho$ is in the lowest quartile, the middle quartiles, or the highest quartile, we conclude, respectively, that using Ifo variables significantly reduces, insignificantly changes, or significantly improves GDPforecast accuracy.

We used analogous tests to determine which filtering and aggregation methods produced better GDP forecasts. We assigned 0 to AD filtering, 1 to $\mathrm{AD} / \mathrm{AMA}$ filtering, 0 to stock aggregation, and 1 to flow aggregation (analogous tests follow from reverse assignments). For each classification, we let $\varphi$ denote the sum of the numerical values in the 50\%-best-forecasting models divided by 3 in monthly cases or divided by 6 in quarterly cases. Then, $0 \leq \varphi \leq 1$ and, if $\varphi$ is uniformly distributed, its bottom quartile spans $[0.0, .25]$, its middle quartiles span $[.25,75]$, and its top quartile spans $[.75,1.0]$. Thus, for a particular classification, if $\varphi$ is in the lowest quartile, the middle quartile, or the highest quartile, we conclude, respectively, that choosing the zero option significantly improves GDP forecasting accuracy, choosing either option insignificantly affects GDP forecasting accuracy, and choosing the unit option significantly improves GDP forecasting accuracy.

Recall that we are forecasting AD-filtered GDP. We could transform the forecasts of filtered GDP back to the original form of GDP by unnormalizing the forecasts using the standard deviation and mean of filtered GDP and undifferencing the result. Frequently, the backtransformed original-form 
forecasts are more accurate, because the restored trends and seasonalities are purely deterministic, hence, perfectly predictable.

\section{Conclusions}

$\mathrm{NRMSFE}_{h}$ and $\mathrm{R}_{f, h}^{2}$ of the filtered GDP forecasts in tables $2-7$ are summarized in table 8 and imply the following six general conclusions.

1. Monthly GDP forecasts are feasible. Estimating a monthly VAR model of quarterly-observed German GDP and monthly-observed indicators of the German economy, using Kalman-filtering-based MLE to produce monthly GDP forecasts, is feasible only if the variables are in compatible cyclical form and not too many parameters are estimated. We estimated unrestricted $\operatorname{VAR}(2)$ models of 2-4 variables, with 15-42 parameters, using 408 monthly and 96 quarterly in-sample periods. Estimating monthly models using monthly-quarterly data seems essential for producing accurate monthly GDP forecasts, especially short-term forecasts, because, even though we can transform quarterly models estimated with purely-quarterly data into monthly models, generally, such transformed models are not expected to produce accurate monthly forecasts.

2. Monthly models produce better short-term GDP forecasts. Monthly models 1-3 produce better short-term GDP forecasts (1-3 months ahead) than the best quarterly-short-term GDP forecasts (1 quarter ahead) produced by model 14. Both monthly- and quarterly-short-term GDP forecasts are not inefficient $\left(\mathrm{NRMSFE}_{h}<1\right)$. The greater accuracy of the monthlyshort-term GDP forecasts should provide sufficient motivation for estimating monthly models, using quarterly-observed GDP and monthly-observed indicators, for producing monthly-short-term GDP forecasts.

3. Quarterly models produce better long-term GDP forecasts. Every monthly model produced inefficient monthly-long-term GDP forecasts (average $\mathrm{NRMSFE}_{h}$ of 1-24 months ahead $>1$ ) which should be disregarded. Every quarterly model produced not inefficient, hence, at least tentatively acceptable, quarterly long-term GDP forecasts (average $\mathrm{NRMSFE}_{h}$ of 1-8 quarters ahead $<1$ ).

4. Ifo variables improve long-term GDP forecasts. After disregarding monthly-long-term GDP forecasts, we have monthly-short-term, quarterlyshort-term, and quarterly-long-term cases in table 8. In these cases, $\rho$ is, respectively, 1.125, 1.400, and 1.118, which implies that using the Ifo variables insignificantly improves monthly-short-term or quarterly-long-term GDP forecasts, but significantly improves quarterly-short-term GDP forecasts (use of $\rho$ is explained in section 5).

5. Aggregation and filtering choices insignificantly affect GDP forecasts. In the monthly-short-term case in table 8 , the filtering $\varphi=0$, which implies that AD filtering produces significantly better GDP forecasts, and the aggregation $\varphi$ is irrelevant. In the quarterly cases, the aggregation $\varphi=.500$ and .667 , and the filtering $\varphi=.500$ and .333 , which implies that how we aggregate or filter has no significant effect on GDP forecasts (use of $\varphi$ is explained in 
section 5). Thus, choosing AD filtering makes a difference - improves GDP forecasts - only in the monthly-short-term case.

6. Extensions to mixed-frequency forecasting with larger models. We might want to estimate larger models, with more variables and more parameters, but the present experience suggests that the present models are at the limit of what MLE can handle, especially with mixed-frequency data. To estimate larger models with mixed-frequency data, we should not use MLE, but should use a noniterative finite-step estimation method. For example, Chen and Zadrozny [2] developed and illustrated the extended Yule-Walker (XYW) method, a linear 2-step GMM method (Hansen [5]) for estimating a VAR model with mixed-frequency data. Being linear and 2-step, the XYW method can be implemented automatically and should be able to handle much larger models than MLE can handle. Mittnik [7], [8], [9] developed and illustrated a linear 2 -step method for estimating a state-space model with singlefrequency data and using the estimated model for forecasting. Extending this method to mixed-frequency data could be more attractive, because, although the two methods have comparable numerical properties, state-space models are more general. Often, a low-dimensional state-space model can fit data well, which even a many-lag VAR model cannot.

\section{References}

1. Box, G.E.P. and G.M. Jenkins (1976), Time Series Analysis, Forecasting and Control, San Francisco, CA: Holden-Day

2. Chen, B. and P.A. Zadrozny (1998), An Extended Yule-Walker Method for Estimating Vector Autoregressive Models with Mixed-Frequency Data, pp. 47-73 in Advances in Econometrics: Messy Data-Missing Observations, Outliers, and Mixed-Frequency Data, Vol. 13, T.B. Fomby and R.C. Hill (eds.), Greenwich, CT: JAI Press

3. Doan, T.A. (2000), RATS Reference Manual, Version 5, Evanston, IL: Estima

4. Flaig, G. (2003), Seasonal and Cyclical Properties of Ifo Business Test Variables, Journal of Economics and Statistics 223: 556-570

5. Hansen, L.P. (1982), Large Sample Properties of Generalized Method of Moments Estimators, Econometrica 50: 1029-1054

6. Ljung, G.M. and G.P. Box (1978), On a Measure of Fit in Time Series Models, Biometrika 65: 297-303

7. Mittnik, S. (1990), Macroeconomic Forecasting Experience with Balanced State Space Models, International Journal of Forecasting 6: 337-348

8. Mittnik, S. (1990), Forecasting with Balanced State Space Representations of Multivariate Distributed Lag Models, Journal of Forecasting 9: 207-218

9. Mittnik, S. (1992), Forecasting International Growth Rates with Leading Indicators: A System-Theoretic Approach, Computers and Mathematics with Applications 24: 31-41

10. Zadrozny, P.A. (2000), Estimating a Multivariate ARMA Model with MixedFrequency Data: An Application to Forecasting U.S. GNP at Monthly Intervals, working paper, Bureau of Labor Statistics, Washington, DC 
GDP

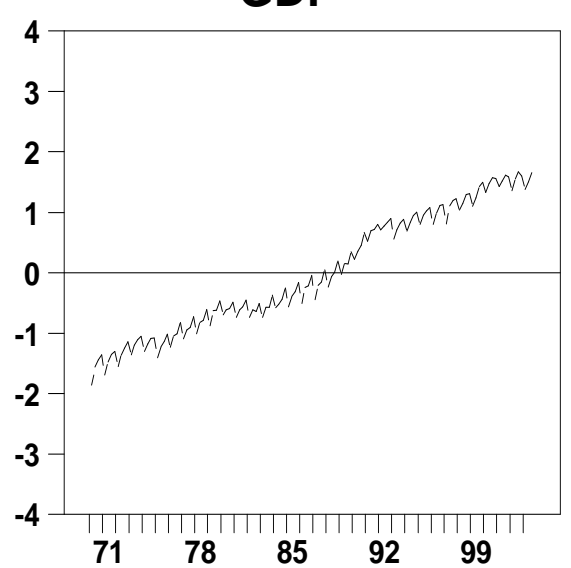

PRD

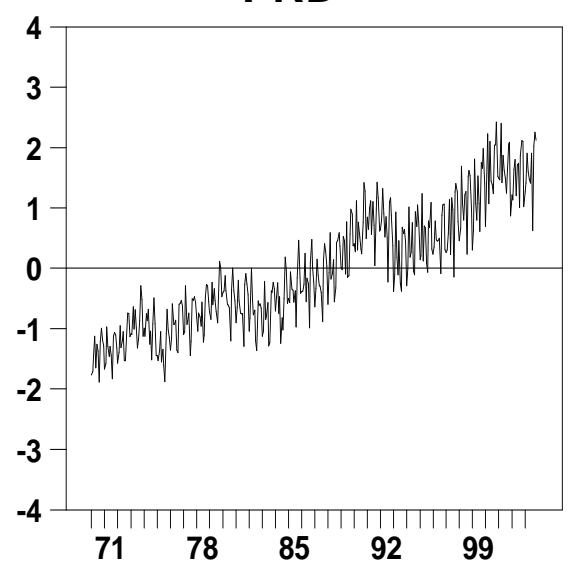

CUR

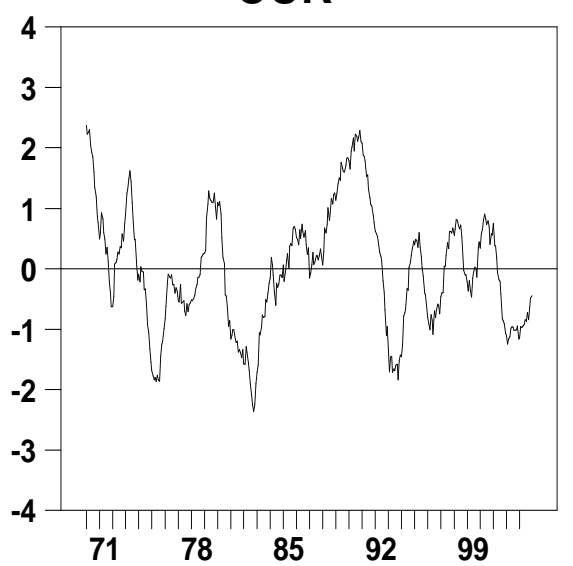

EXP

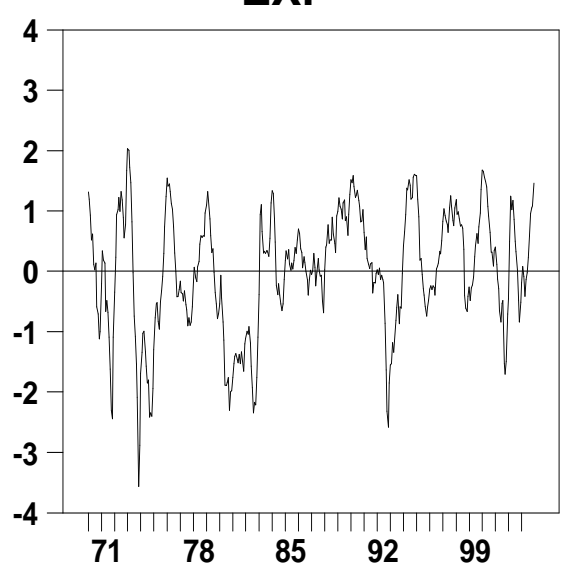

Fig. 1. Monthly, Original Variables 

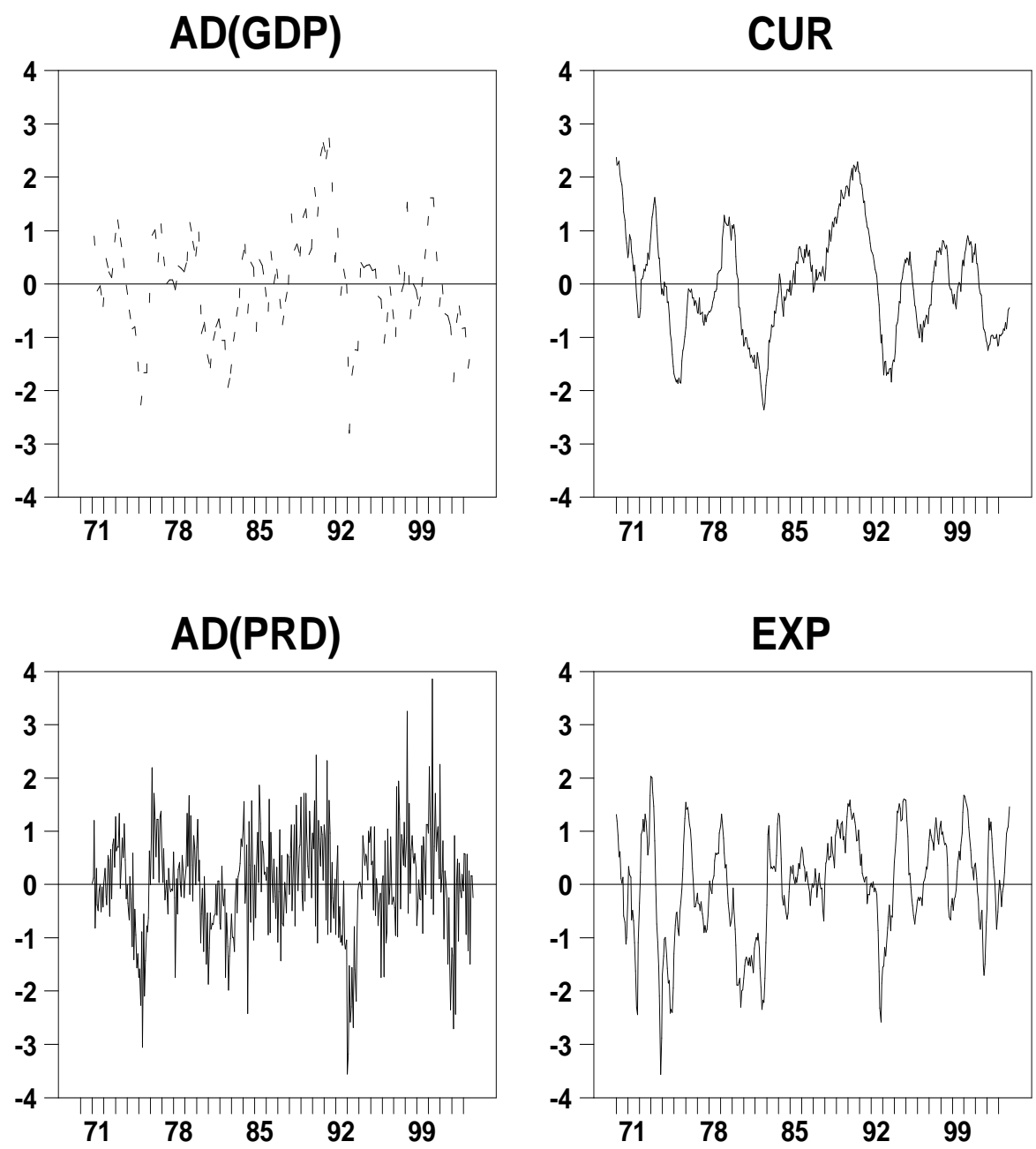

Fig. 2. Monthly, AD Filtered 


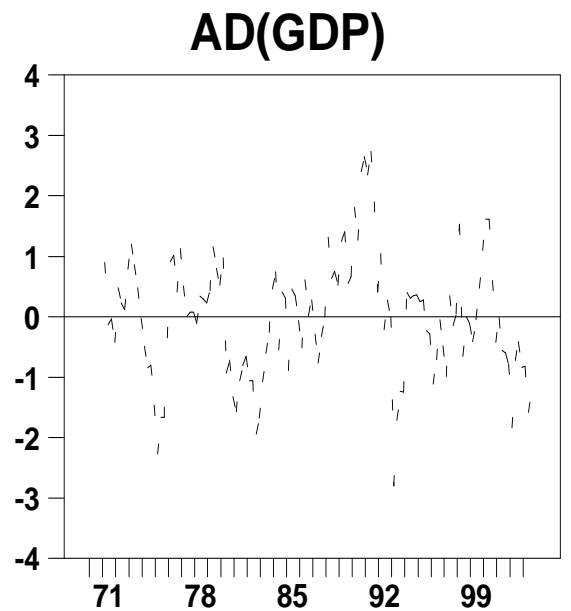

CUR
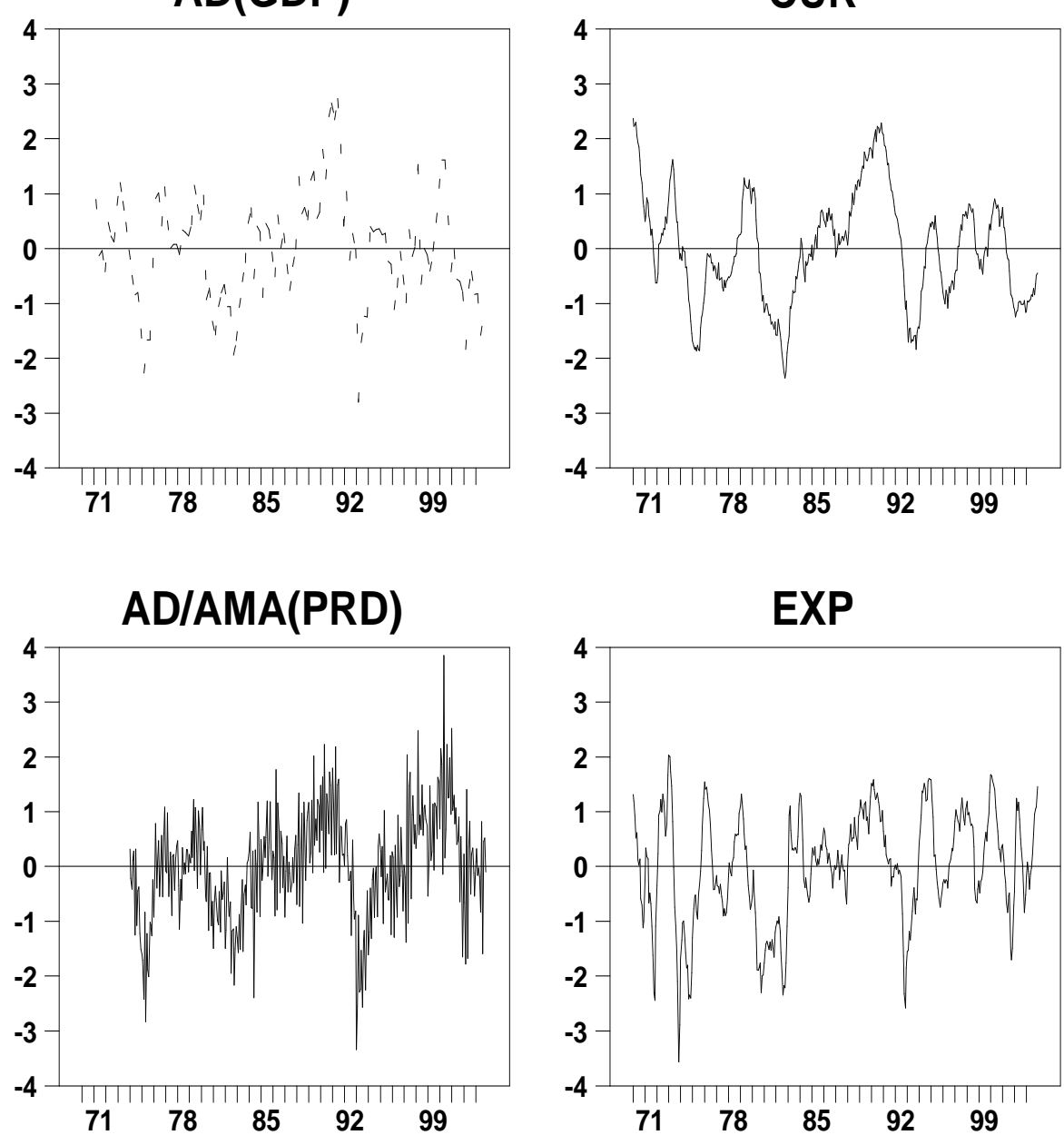

EXP

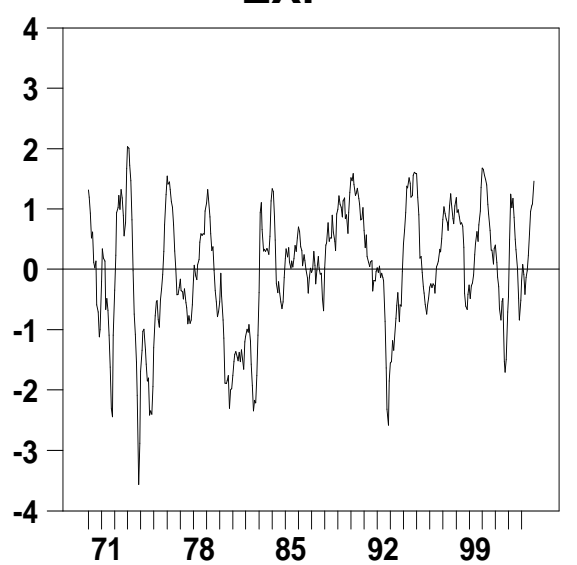

Fig. 3. Monthly, AD/AMA Filtered 


\section{GDP}

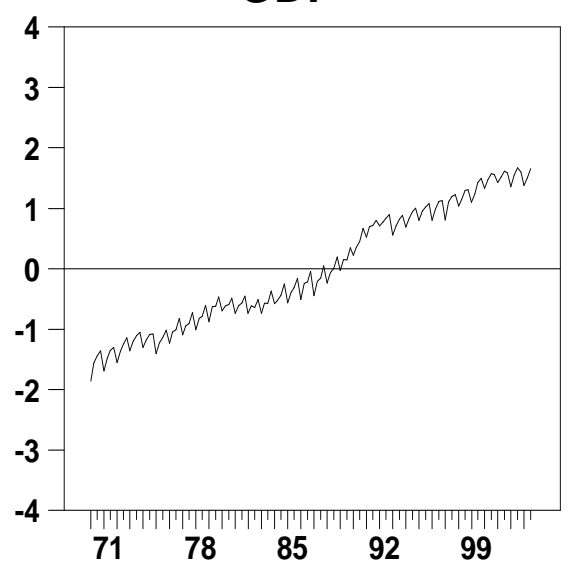

PRD

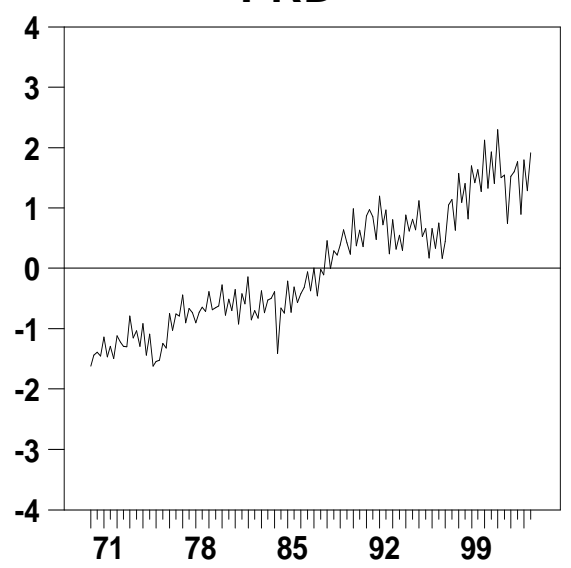

CUR

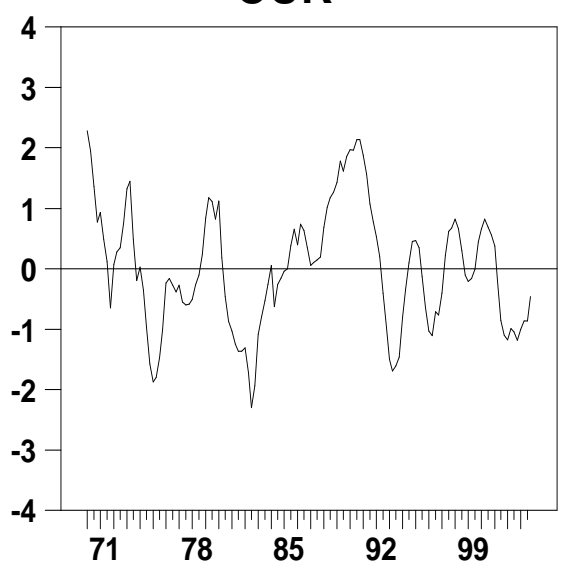

EXP

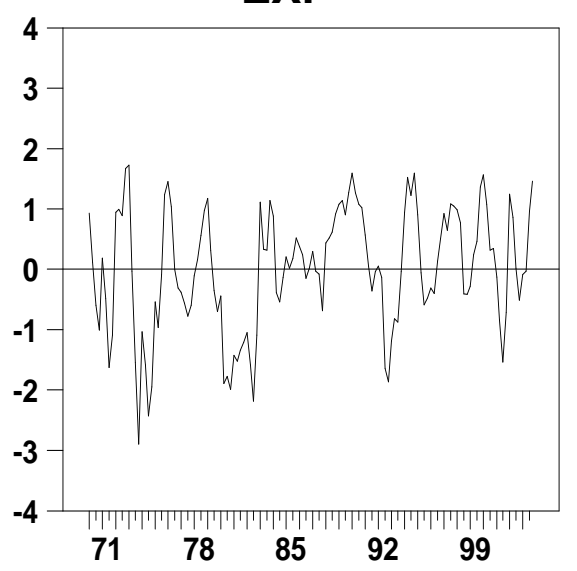

Fig. 4. Quarterly, Stocks, Original Variables 


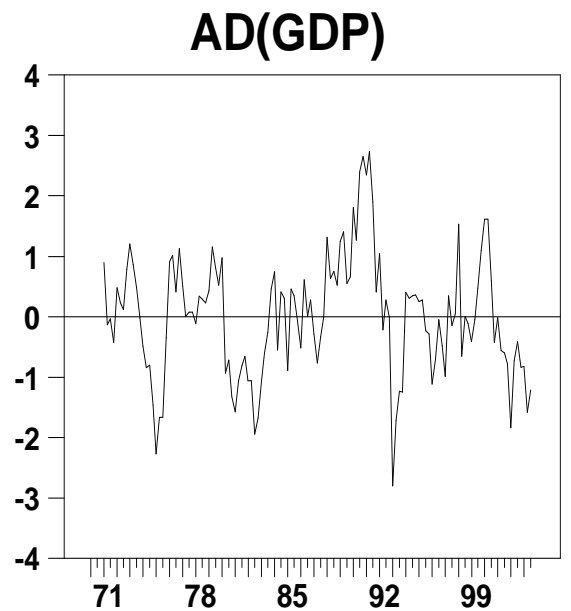

CUR

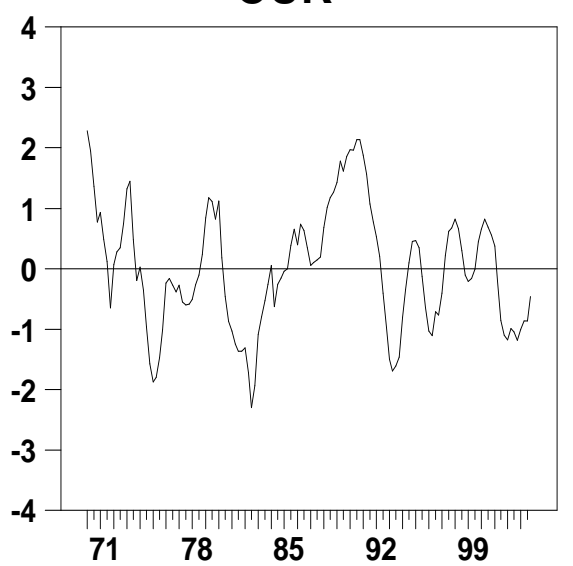

AD(PRD)

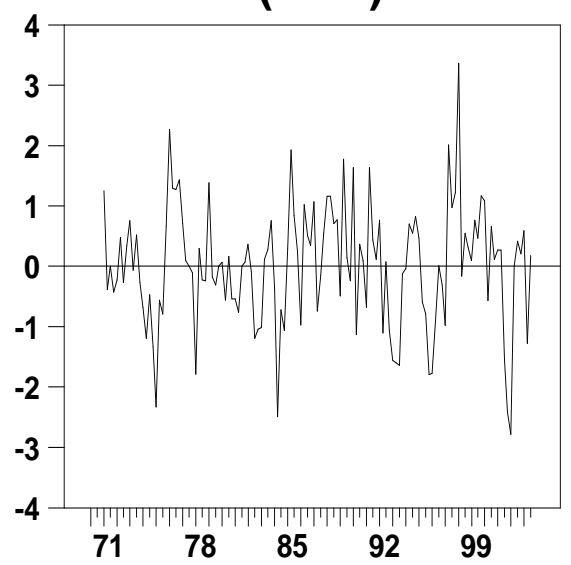

EXP

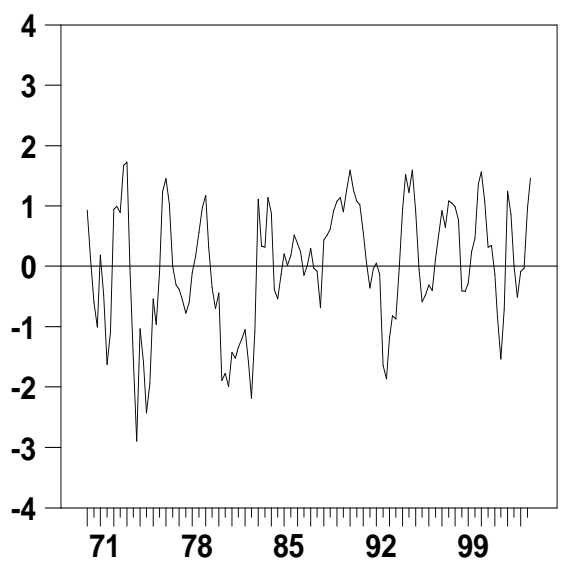

Fig. 5. Quarterly, Stocks, AD Filtered 

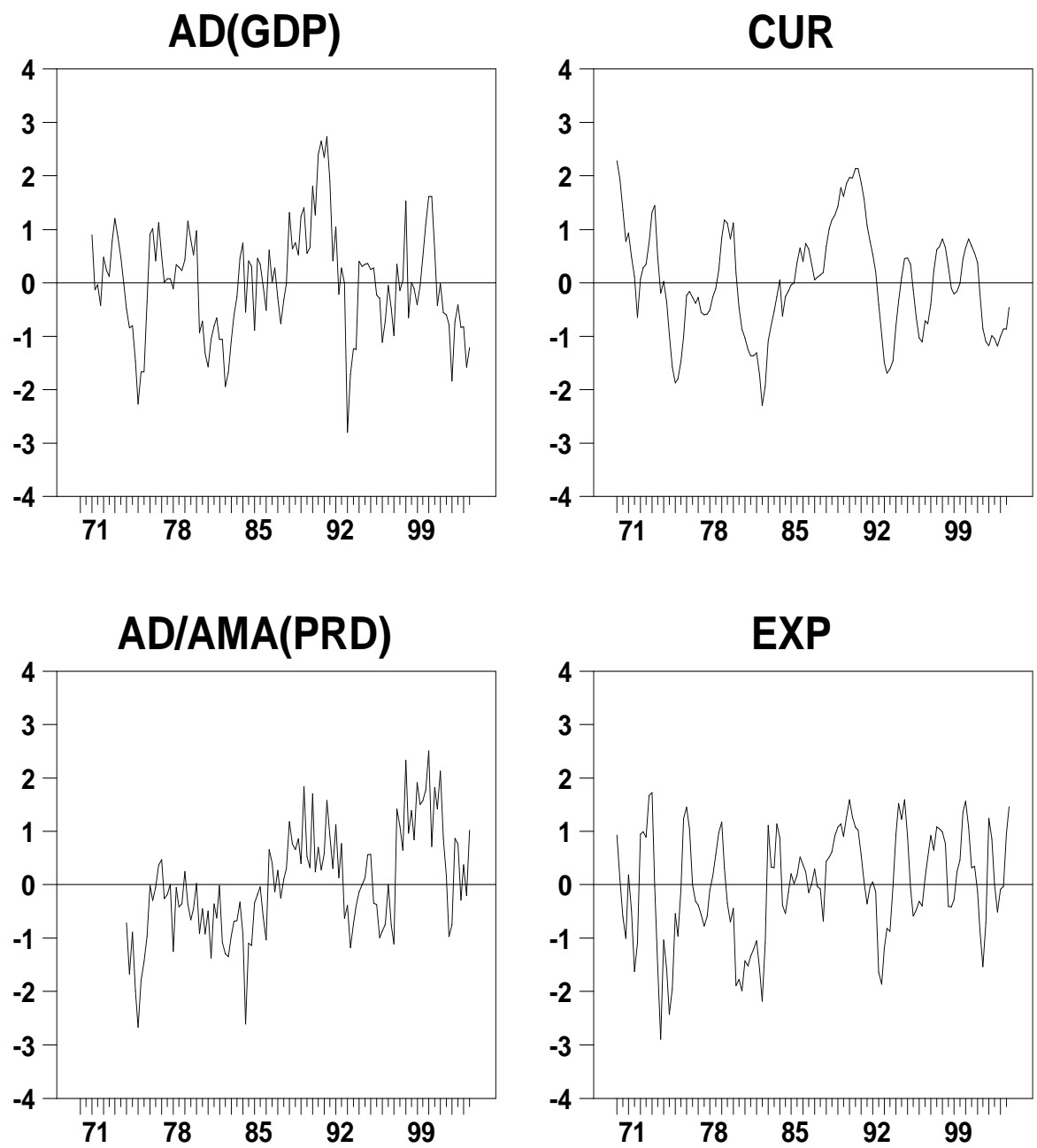

Fig. 6. Quarterly, Stocks, AD/AMA Filtered 
GDP

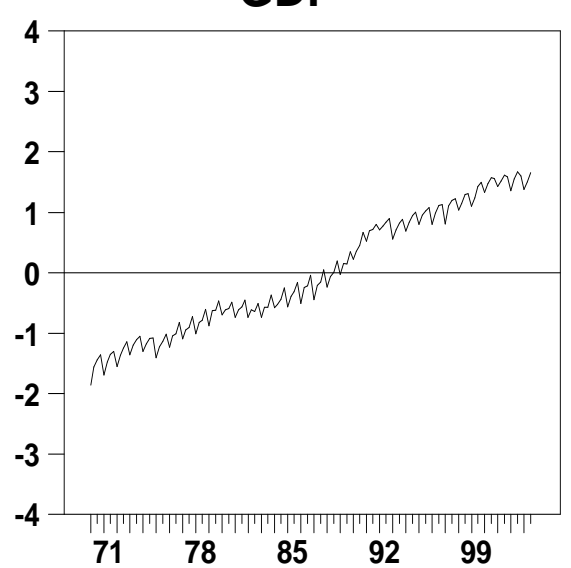

PRD

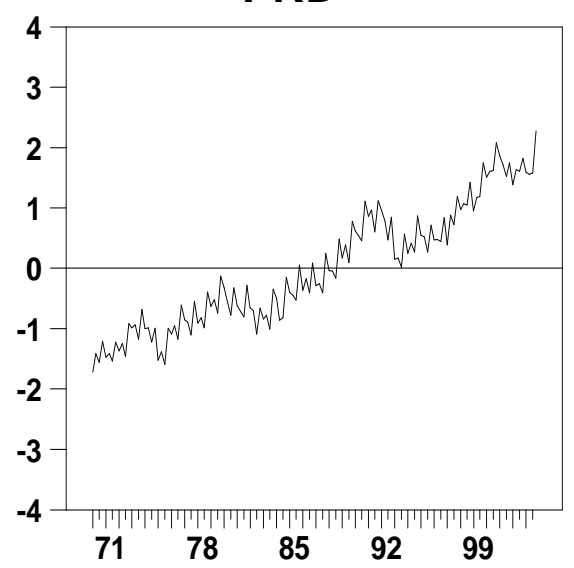

CUR

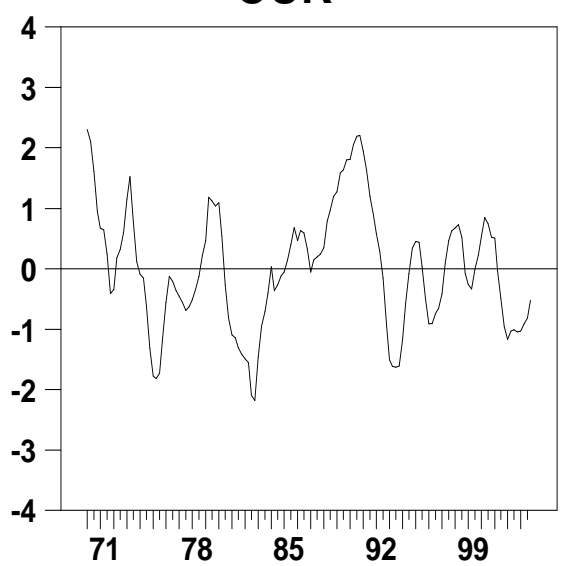

EXP

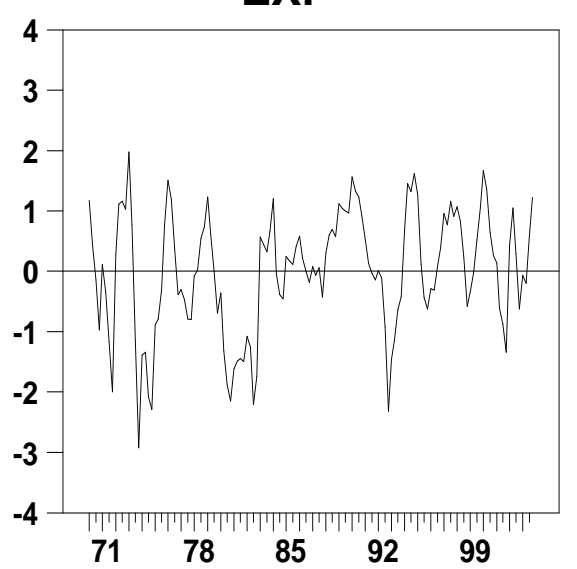

Fig. 7. Quarterly, Flows, Original Variables 

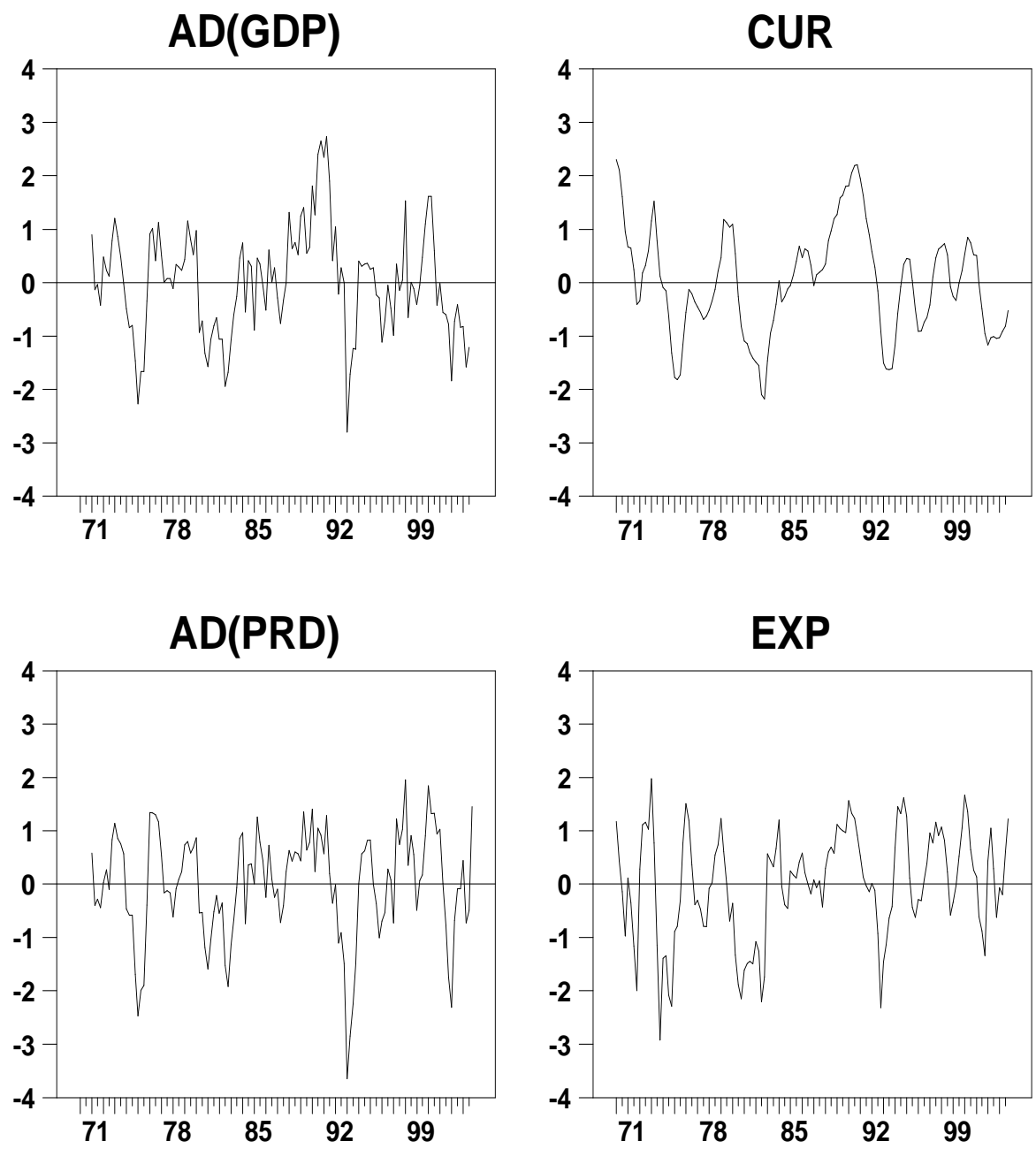

Fig. 8. Quarterly, Flows, AD Filtered 


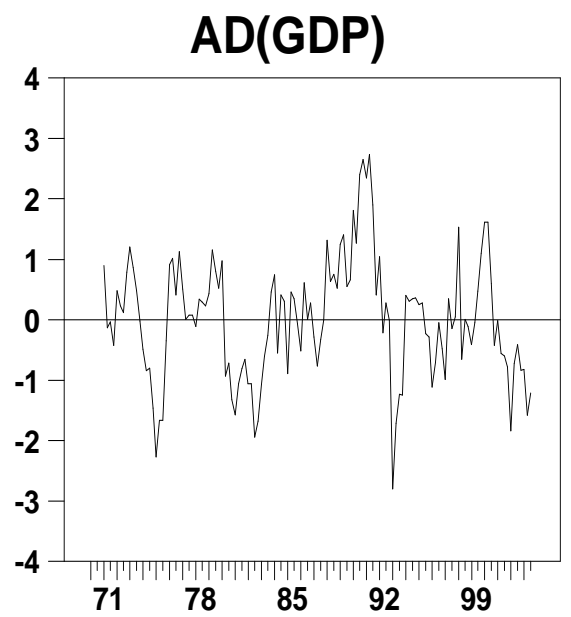

CUR
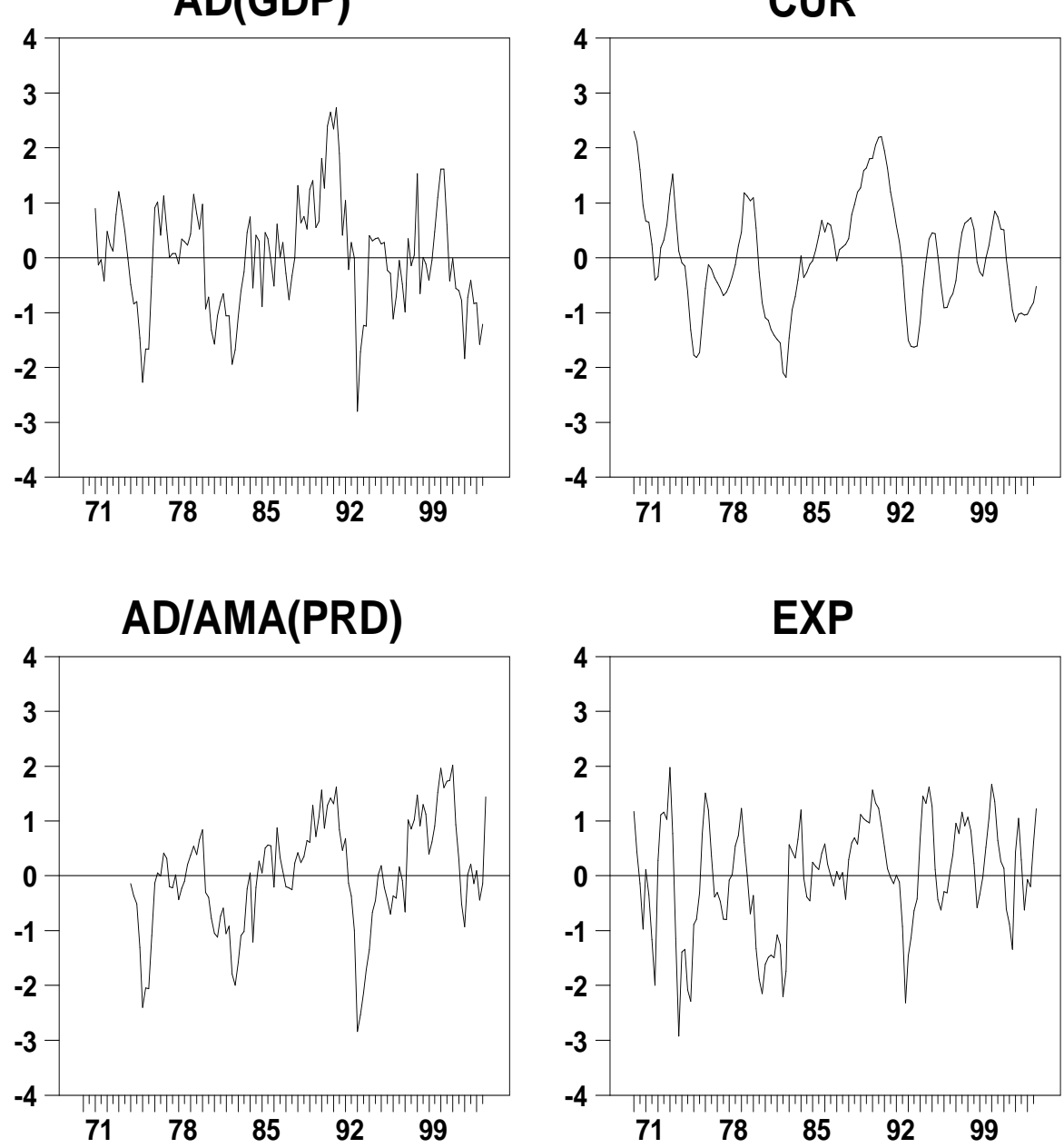

EXP

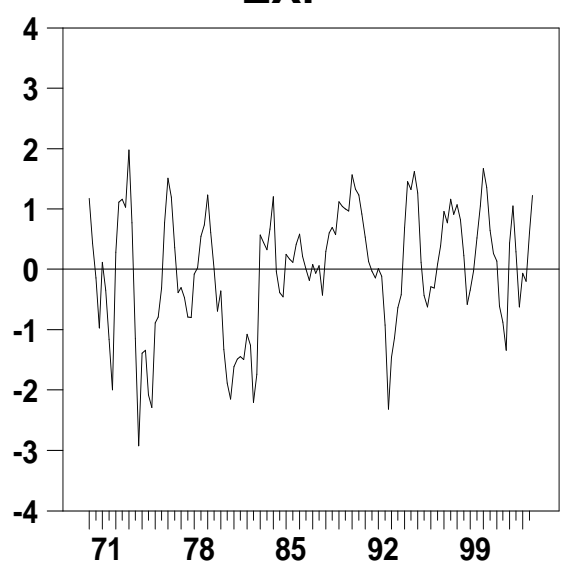

Fig. 9. Quarterly, Flows, AD/AMA Filtered 
Table 1. $\mathrm{R}_{e}^{2}$ of Estimated $\operatorname{VAR}(2)$ Models

\begin{tabular}{cccccc}
\hline \multicolumn{1}{c}{ Model } & GDP & PRD & CUR & EXP \\
\hline 1 & mon, 4 vars, AD & .804 & .522 & .966 & .904 \\
2 & mon, 3 vars, AD & .812 & .478 & .958 & - \\
3 & mon, 2 vars, AD & .850 & .488 & - & - \\
& & & & & \\
4 & mon, 4 vars, AD/AMA & .783 & .608 & .966 & .903 \\
5 & mon, 3 vars, AD/AMA & .780 & .592 & .959 & - \\
6 & mon, 2 vars, AD/AMA & .516 & .567 & - & - \\
& & & & & \\
7 & qrt, 4 vars, stocks, AD & .735 & .239 & .882 & .606 \\
8 & qrt, 3 vars, stocks, AD & .663 & .201 & .867 & - \\
9 & qrt, 2 vars, stocks, AD & .592 & .145 & - & - \\
& & & & & \\
10 & qrt, 4 vars, stocks, AD/AMA & .734 & .553 & .882 & .606 \\
11 & qrt, 3 vars, stocks, AD/AMA & .663 & .530 & .867 & - \\
12 & qrt, 2 vars, stocks, AD/AMA & .592 & .499 & - & - \\
& & & & & \\
13 & qrt, 4 vars, flows, AD & .725 & .715 & .912 & .626 \\
14 & qrt, 3 vars, flows, AD & .685 & .682 & .900 & - \\
15 & qrt, 2 vars, flows, AD & .606 & .600 & - & - \\
& & & & & \\
16 & qrt, 4 vars, flows, AD/AMA & .721 & .822 & .911 & .632 \\
17 & qrt, 3 vars, flows, AD/AMA & .690 & .802 & .901 & - \\
18 & qrt, 2 vars, flows, AD/AMA & .597 & .739 & - & - \\
\hline
\end{tabular}

Tables 1-8 display estimation $\mathrm{R}$-squared $\left(\mathrm{R}_{e}^{2}\right)$, forecasting $\mathrm{R}$-squared $\left(\mathrm{R}_{f, h}^{2}\right)$, normalized root mean squared forecast error $\left(\mathrm{NRMSFE}_{h}\right)$, and Theil U statistics, for $h \geq 1$ forecast periods ahead, all defined in section 5 . 
Table 2. GDP Forecast Accuracy, Monthly, AD Filtered

\begin{tabular}{|c|c|c|c|}
\hline \multicolumn{4}{|c|}{ Model 1: $\operatorname{VAR}(2)$ of 4 variables $\mathrm{AD}(\mathrm{GDP}), \mathrm{AD}(\mathrm{PRD}), \mathrm{CUR}, \mathrm{EXP}$} \\
\hline months ahead & $\mathrm{NRMSFE}_{h}$ & $\mathrm{R}_{f, h}^{2}$ & Theil U \\
\hline 1 & .723 & .477 & .724 \\
\hline 2 & .802 & .357 & .796 \\
\hline 3 & .852 & .274 & .846 \\
\hline 4 & .947 & .103. & .787 \\
\hline 5 & .993 & .014 & .824 \\
\hline 6 & 1.02 & -.404 & .846 \\
\hline 9 & 1.22 & -.488 & .900 \\
\hline 12 & 1.36 & -.850 & .795 \\
\hline 18 & 1.30 & -.690 & .756 \\
\hline 24 & 1.16 & -.346 & .671 \\
\hline average $1-24$ months & 1.18 & -.392 & .781 \\
\hline \multicolumn{4}{|c|}{ Model 2: $\operatorname{VAR}(2)$ of 3 variables $\mathrm{AD}(\mathrm{GDP}), \mathrm{AD}(\mathrm{PRD}), \mathrm{CUR}$} \\
\hline months ahead & $\mathrm{NRMSFE}_{h}$ & $\mathrm{R}_{f, h}^{2}$ & Theil U \\
\hline 1 & .731 & .466 & .725 \\
\hline 2 & .846 & .284 & .839 \\
\hline 3 & .917 & .159 & .910 \\
\hline 4 & 1.02 & -.040 & .847 \\
\hline 5 & 1.12 & -.254 & .934 \\
\hline 6 & 1.15 & -.323 & .958 \\
\hline 9 & 1.39 & -.932 & 1.02 \\
\hline 12 & 1.54 & -1.37 & .896 \\
\hline 18 & 1.46 & -1.13 & .852 \\
\hline 24 & 1.33 & -.769 & .771 \\
\hline average $1-24$ months & 1.32 & -.742 & .872 \\
\hline \multicolumn{4}{|c|}{ Model 3: $\operatorname{VAR}(2)$ of 2 variables $\mathrm{AD}(\mathrm{GDP}), \mathrm{AD}(\mathrm{PRD})$} \\
\hline months ahead & $\mathrm{NRMSFE}_{h}$ & $\mathrm{R}_{f, h}^{2}$ & Theil U \\
\hline 1 & .711 & .494 & .705 \\
\hline 2 & .799 & .362 & .792 \\
\hline 3 & .920 & .154 & .913 \\
\hline 4 & .959 & .080 & .797 \\
\hline 5 & .962 & .075 & .799 \\
\hline 6 & 1.02 & -.040 & .846 \\
\hline 9 & 1.07 & -.144 & .785 \\
\hline 12 & 1.17 & -.369 & .684 \\
\hline 18 & 1.25 & -.563 & .656 \\
\hline 24 & 1.11 & -.232 & .644 \\
\hline average 1-24 months & 1.08 & -.166 & .719 \\
\hline
\end{tabular}


Table 3. GDP Forecast Accuracy, Monthly, AD/AMA Filtered

\begin{tabular}{|c|c|c|c|}
\hline \multicolumn{4}{|c|}{ Model 4: VAR(2) of 4 variables $\mathrm{AD}(\mathrm{GDP}), \mathrm{AD} / \mathrm{AMA}(\mathrm{PRD}), \mathrm{CUR}, \mathrm{EXP}$} \\
\hline months ahead & $\mathrm{NRMSFE}_{h}$ & $\mathrm{R}_{f, h}^{2}$ & Theil U \\
\hline 1 & .820 & .328 & .813 \\
\hline 2 & .816 & .334 & .810 \\
\hline 3 & .821 & .326 & .814 \\
\hline 4 & .932 & .131 & .774 \\
\hline 5 & .993 & .014 & .792 \\
\hline 6 & .981 & .038 & .815 \\
\hline 9 & 1.18 & -.392 & .873 \\
\hline 12 & 1.31 & -.716 & .763 \\
\hline 18 & 1.27 & -.613 & .740 \\
\hline 24 & 1.12 & -.254 & .649 \\
\hline average $1-24$ months & 1.15 & -.323 & .761 \\
\hline \multicolumn{4}{|c|}{ Model 5: $\operatorname{VAR}(2)$ of 3 variables $\mathrm{AD}(\mathrm{GDP}), \mathrm{AD} / \mathrm{AMA}(\mathrm{PRD}), \mathrm{CUR}$} \\
\hline months ahead & NRMSFE $_{h}$ & $\mathrm{R}_{f, h}^{2}$ & Theil U \\
\hline 1 & .814 & .337 & .808 \\
\hline 2 & .870 & .243 & .863 \\
\hline 3 & .882 & .222 & .875 \\
\hline 4 & .966 & .067 & .802 \\
\hline 5 & 1.07 & -.145 & .888 \\
\hline 6 & 1.06 & -.124 & .882 \\
\hline 9 & 1.23 & -.513 & .906 \\
\hline 12 & 1.34 & -.796 & .783 \\
\hline 18 & 1.33 & -.769 & .774 \\
\hline 24 & 1.19 & -.416 & .691 \\
\hline average $1-24$ months & 1.21 & -.464 & .804 \\
\hline \multicolumn{4}{|c|}{ Model 6: $\operatorname{VAR}(2)$ of 2 variables $\mathrm{AD}(\mathrm{GDP}), \mathrm{AD} / \mathrm{AMA}(\mathrm{PRD})$} \\
\hline months ahead & $\mathrm{NRMSFE}_{h}$ & $\mathrm{R}_{f, h}^{2}$ & Theil U \\
\hline 1 & .935 & .126 & .927 \\
\hline 2 & 1.02 & -.040 & 1.01 \\
\hline 3 & .997 & .006 & .989 \\
\hline 4 & 1.11 & -.232 & .923 \\
\hline 5 & 1.23 & -.513 & .936 \\
\hline 6 & 1.13 & -.277 & .939 \\
\hline 9 & 1.10 & -.210 & .808 \\
\hline 12 & 1.06 & -.124 & .617 \\
\hline 18 & 1.09 & -.188 & .634 \\
\hline 24 & 1.07 & -.145 & .623 \\
\hline average $1-24$ months & 1.07 & -.145 & .729 \\
\hline
\end{tabular}


Table 4. GDP Forecast Accuracy, Quarterly, Stocks, AD Filtered

\begin{tabular}{cccc}
\hline \multicolumn{4}{c}{ Model 7: VAR(2) of 4 variables AD(GDP), AD(PRD), CUR, EXP } \\
\hline quarters ahead & NRMSFE $_{h}$ & $\mathrm{R}_{f, h}^{2}$ & Theil U \\
\hline 1 & .812 & .341 & .872 \\
2 & .822 & .324 & .730 \\
3 & .846 & .284 & .648 \\
4 & .876 & .233 & .512 \\
6 & .928 & .139 & .512 \\
8 & .977 & .045 & .510 \\
average 1-8 quarters & .889 & .210 & .600
\end{tabular}

Model 8: VAR(2) of 3 variables $\mathrm{AD}(\mathrm{GDP}), \mathrm{AD}(\mathrm{PRD}), \mathrm{CUR}$

\begin{tabular}{cccc}
\hline quarters ahead & $\mathrm{NRMSFE}_{h}$ & $\mathrm{R}_{f, h}^{2}$ & Theil U \\
\hline 1 & .765 & .415 & .821 \\
2 & .751 & .436 & .687 \\
3 & .764 & .416 & .610 \\
4 & .788 & .379 & .482 \\
6 & .837 & .299 & .482 \\
8 & .877 & .231 & .480 \\
average 1-8 quarters & .807 & .349 & .565
\end{tabular}

Model 9: $\operatorname{VAR}(2)$ of 2 variables $\mathrm{AD}(\mathrm{GDP}), \mathrm{AD}(\mathrm{PRD}))$

\begin{tabular}{cccc}
\hline quarters ahead & NRMSFE $_{h}$ & $\mathrm{R}_{f, h}^{2}$ & Theil U \\
\hline 1 & .845 & .286 & .907 \\
2 & .837 & .299 & .759 \\
3 & .842 & .291 & .674 \\
4 & .856 & .267 & .533 \\
6 & .889 & .210 & .533 \\
8 & .919 & .155 & .530 \\
average 1-8 quarters & .871 & .241 & .625 \\
\hline
\end{tabular}


Table 5. GDP Forecast Accuracy, Quarterly, Stocks, AD/AMA Filtered

\begin{tabular}{cccc}
\hline \multicolumn{3}{c}{ Model 10: VAR(2) of 4 variables $\mathrm{AD}(\mathrm{GDP}), \mathrm{AD} / \mathrm{AMA}(\mathrm{PRD}), \mathrm{CUR}, \mathrm{EXP}$} \\
\hline quarters ahead & $\mathrm{NRMSFE}_{h}$ & $\mathrm{R}_{f, h}^{2}$ & Theil U \\
\hline 1 & .811 & .342 & .870 \\
2 & .790 & .376 & .729 \\
3 & .823 & .323 & .647 \\
4 & .858 & .264 & .512 \\
6 & .931 & .133 & .511 \\
8 & .991 & .018 & .509 \\
average 1-8 quarters & .883 & .220 & .599
\end{tabular}

Model 11: VAR(2) of 3 variables AD(GDP), AD/AMA(PRD), CUR

\begin{tabular}{cccc}
\hline quarters ahead & NRMSFE $_{h}$ & $\mathrm{R}_{f, h}^{2}$ & Theil U \\
\hline 1 & .780 & .392 & .837 \\
2 & .760 & .422 & .700 \\
3 & .768 & .410 & .622 \\
4 & .786 & .382 & .492 \\
6 & .838 & .298 & .492 \\
8 & .888 & .211 & .489 \\
average 1-8 quarters & .812 & .341 & .576
\end{tabular}

Model 12: $\operatorname{VAR}(2)$ of 2 variables $\mathrm{AD}(\mathrm{GDP}), \mathrm{AD} / \mathrm{AMA}(\mathrm{PRD})$

\begin{tabular}{cccc}
\hline quarters ahead & NRMSFE $_{h}$ & $\mathrm{R}_{f, h}^{2}$ & Theil U \\
\hline 1 & .844 & .288 & .906 \\
2 & .825 & .319 & .758 \\
3 & .828 & .314 & .673 \\
4 & .842 & .291 & .532 \\
6 & .881 & .224 & .532 \\
8 & .918 & .157 & .530 \\
average 1-8 quarters & .863 & .255 & .624 \\
\hline
\end{tabular}


Table 6. GDP Forecast Accuracy, Quarterly, Flows, AD Filtered

\begin{tabular}{cccc}
\hline \multicolumn{3}{c}{ Model 13: VAR(2) of 4 variables } & AD(GDP), AD(PRD), CUR, EXP \\
\hline quarters ahead & NRMSFE $_{h}$ & $\mathrm{R}_{f, h}^{2}$ & Theil U \\
\hline 1 & .786 & .382 & .844 \\
2 & .752 & .434 & .706 \\
3 & .752 & .434 & .627 \\
4 & .769 & .409 & .496 \\
6 & .848 & .281 & .496 \\
8 & .913 & .166 & .493 \\
average 1-8 quarters & .814 & .337 & .581
\end{tabular}

\begin{tabular}{|c|c|c|c|}
\hline quarters ahead & $\mathrm{NRMSFE}_{h}$ & $\mathrm{R}_{f, h}^{2}$ & Theil U \\
\hline 1 & .734 & .461 & .787 \\
\hline 2 & .709 & .497 & .659 \\
\hline 3 & .712 & .493 & .585 \\
\hline 4 & .748 & .440 & .463 \\
\hline 6 & .842 & .291 & .463 \\
\hline 8 & .918 & .157 & .460 \\
\hline average $1-8$ quarters & .793 & .371 & .542 \\
\hline \multicolumn{4}{|c|}{ Model 15: $\operatorname{VAR}(2)$ of 2 variables $\mathrm{AD}(\mathrm{GDP}), \mathrm{AD}(\mathrm{PRD}$} \\
\hline quarters ahead & $\mathrm{NRMSFE}_{h}$ & $\mathrm{R}_{f, h}^{2}$ & Theil U \\
\hline 1 & .825 & .319 & .885 \\
\hline 2 & .800 & .360 & .741 \\
\hline 3 & .805 & .352 & .658 \\
\hline 4 & .827 & .316 & .520 \\
\hline 6 & .874 & .236 & .520 \\
\hline 8 & .912 & .168 & .517 \\
\hline average $1-8$ quarters & .849 & .279 & .609 \\
\hline
\end{tabular}


Table 7. GDP Forecast Accuracy, Quarterly, Flows, AD/AMA Filtered

\begin{tabular}{cccc}
\hline \multicolumn{4}{c}{ Model 16: VAR(2) of 4 variables $\mathrm{AD}(\mathrm{GDP}), \mathrm{AD} / \mathrm{AMA}(\mathrm{PRD}), \mathrm{CUR}, \mathrm{EXP}$} \\
\hline quarters ahead & $\mathrm{NRMSFE}_{h}$ & $\mathrm{R}_{f, h}^{2}$ & Theil U \\
\hline 1 & .762 & .419 & .818 \\
2 & .736 & .458 & .685 \\
3 & .767 & .412 & .608 \\
4 & .823 & .323 & .481 \\
6 & .901 & .188 & .481 \\
8 & .905 & .181 & .478 \\
average 1-8 quarters & .834 & .304 & .563
\end{tabular}

Model 17: $\operatorname{VAR}(2)$ of 3 variables $\mathrm{AD}(\mathrm{GDP}), \mathrm{AD} / \mathrm{AMA}(\mathrm{PRD}), \mathrm{CUR}$

\begin{tabular}{cccc}
\hline quarters ahead & NRMSFE $_{h}$ & $\mathrm{R}_{f, h}^{2}$ & Theil U \\
\hline 1 & .819 & .329 & .879 \\
2 & .850 & .278 & .736 \\
3 & .869 & .245 & .653 \\
4 & .872 & .240 & .517 \\
6 & .882 & .222 & .516 \\
8 & .923 & .148 & .514 \\
average 1-8 quarters & .874 & .236 & .605
\end{tabular}

Model 18: $\operatorname{VAR}(2)$ of 2 variables $\mathrm{AD}(\mathrm{GDP}), \mathrm{AD} / \mathrm{AMA}(\mathrm{PRD})$

\begin{tabular}{cccc}
\hline quarters ahead & NRMSFE $_{h}$ & $\mathrm{R}_{f, h}^{2}$ & Theil U \\
\hline 1 & .818 & .331 & .877 \\
2 & .803 & .355 & .734 \\
3 & .809 & .346 & .652 \\
4 & .828 & .314 & .516 \\
6 & .877 & .231 & .516 \\
8 & .920 & .154 & .513 \\
average 1-8 quarters & .851 & .276 & .604 \\
\hline
\end{tabular}


Table 8. GDP Forecast Accuracy, Rankings of All Models

\begin{tabular}{ccccc}
\hline \multicolumn{5}{c}{ Monthly short term: $\mathrm{NRMSFE}_{h}$ and $\mathrm{R}_{f, h}^{2}$ of GDP forecasts 1 month ahead } \\
\hline rank & $\mathrm{NRMSFE}_{h}$ & $\mathrm{R}_{f, h}^{2}$ & variables & model \\
\hline 1 & .711 & .494 & 2 vars, AD & 3 \\
2 & .723 & .477 & 4 vars, AD & 1 \\
3 & .731 & .466 & 3 vars, AD & 5 \\
4 & .814 & .337 & 3 vars, AD/AMA & 4 \\
5 & .820 & .328 & 4 vars, AD/AMA & 6 \\
6 & .935 & .126 & 2 vars, AD/AMA
\end{tabular}

Monthly long term: average $\mathrm{NRMSFE}_{h}$ and $\mathrm{R}_{f, h}^{2}$ of GDP forecasts $1-24$ mons. ahead

\begin{tabular}{ccccc}
\hline rank & $\mathrm{NRMSFE}_{h}$ & $\mathrm{R}_{f, h}^{2}$ & variables & model \\
\hline 1 & 1.07 & -.145 & 2 vars, $\mathrm{AD} / \mathrm{AMA}$ & 6 \\
2 & 1.08 & -.166 & 2 vars, $\mathrm{AD}$ & 3 \\
3 & 1.15 & -.323 & 4 vars, $\mathrm{AD} / \mathrm{AMA}$ & 4 \\
4 & 1.18 & -.392 & 4 vars, $\mathrm{AD}$ & 1 \\
5 & 1.21 & -.464 & 3 vars, $\mathrm{AD} / \mathrm{AMA}$ & 5 \\
6 & 1.32 & -.742 & 3 vars, $\mathrm{AD}$ & 2
\end{tabular}

Quarterly short term: $\mathrm{NRMSFE}_{h}$ and $\mathrm{R}_{f, h}^{2}$ of GDP forecasts 1 quarter ahead

\begin{tabular}{ccccc}
\hline rank & NRMSFE $_{h}$ & $\mathrm{R}_{f, h}^{2}$ & variables & model \\
\hline 1 & .734 & .461 & 3 vars, flows, AD & 14 \\
2 & .762 & .419 & 4 vars, flows, AD/AMA & 16 \\
3 & .765 & .415 & 3 vars, stocks, AD & 8 \\
4 & .780 & .392 & 3 vars, stocks, AD/AMA & 11 \\
5 & .786 & .382 & 4 vars, flows, AD & 13 \\
6 & .811 & .342 & 4 vars, stocks, AD/AMA & 10 \\
7 & .812 & .341 & 4 vars, stocks, AD & 7 \\
8 & .818 & .331 & 2 vars, flows, AD/AMA & 18 \\
9 & .819 & .329 & 3 vars, flows, AD/AMA & 17 \\
10 & .825 & .319 & 2 vars, flows, AD & 15 \\
11 & .844 & .288 & 2 vars, stocks, AD/AMA & 12 \\
12 & .845 & .286 & 2 vars, stocks, AD & 9
\end{tabular}

\begin{tabular}{ccccc}
\multicolumn{5}{c}{ Quarterly long term: average $\mathrm{NRMSFE}_{h}$ and $\mathrm{R}_{f, h}^{2}$ of GDP forecasts $1-8$ qrts. ahead } \\
\hline rank & $\mathrm{NRMSFE}_{h}$ & $\mathrm{R}_{f, h}^{2}$ & variables & model \\
\hline 1 & .793 & .371 & 3 vars, flows, AD & 14 \\
2 & .807 & .349 & 3 vars, stocks, AD & 8 \\
3 & .812 & .341 & 3 vars, stocks, AD/AMA & 11 \\
4 & .814 & .337 & 4 vars, flows, AD & 13 \\
5 & .834 & .304 & 4 vars, flows, AD/AMA & 16 \\
6 & .849 & .279 & 2 vars, flows, AD & 15 \\
7 & .851 & .276 & 2 vars, flows, AD/AMA & 18 \\
8 & .863 & .255 & 2 vars, stocks, AD/AMA & 12 \\
9 & .871 & .241 & 2 vars, stocks, AD & 9 \\
10 & .874 & .236 & 3 vars, flows, AD/AMA & 17 \\
11 & .883 & .220 & 4 vars, stocks, AD/AMA \\
12 & .889 & .210 & 4 vars, stocks, AD & 10 \\
\hline
\end{tabular}




\section{CESifo Working Paper Series}

(for full list see www.cesifo.de)

1140 Michael Rauscher, Economic Growth and Tax-Competing Leviathans, February 2004

1141 Ernst Fehr and Jean-Robert Tyran, Money Illusion and Coordination Failure, February 2004

1142 Ingo Vogelsang, Network Utilities in the U.S. - Sector Reforms without Privatization, March 2004

1143 Marc-Andreas Muendler, Estimating Production Functions When Productivity Change is Endogenous, March 2004

1144 Sascha O. Becker, Samuel Bentolila, Ana Fernandes, and Andrea Ichino, Job Insecurity and Children's Emancipation, March 2004

1145 Pascalis Raimondos-Møller and Alan D. Woodland, Non-Preferential Trading Clubs, March 2004

1146 Robert Fenge and Matthias Wrede, EU Regional Policy: Vertical Fiscal Externalities and Matching Grants, March 2004

1147 Chi-Yung Ng and John Whalley, Geographical Extension of Free Trade Zones as Trade Liberalization: A Numerical Simulation Approach, March 2004

1148 Marc-Andreas Muendler, Trade, Technology, and Productivity: A Study of Brazilian Manufacturers, 1986-1998, March 2004

1149 Eugene Beaulieu, Vivek H. Dehejia, and Hazrat-Omar Zakhilwal, International Trade, Labour Turnover, and the Wage Premium: Testing the Bhagwati-Dehejia Hypothesis for Canada, March 2004

1150 Giorgio Brunello and Francesca Gambarotto, Agglomeration Effects on EmployerProvided Training: Evidence from the UK, March 2004

1151 S. Brock Blomberg, Gregory D. Hess, and Athanasios Orphanides, The Macroeconomic Consequences of Terrorism, March 2004

1152 Bodo Sturm and Joachim Weimann, Unilateral Emissions Abatement: An Experiment, March 2004

1153 Wolfgang Ochel, Welfare-to-Work Experiences with Specific Work-First Programmes in Selected Countries, March 2004

1154 Jan K. Brueckner and Eric Pels, European Airline Mergers, Alliance Consolidation, and Consumer Welfare, March 2004 
1155 Aaron Tornell, Frank Westermann, and Lorenza Martínez, NAFTA and Mexico's Economic Performance, March 2004

1156 George Economides, Sarantis Kalyvitis, and Apostolis Philippopoulos, Do Foreign Aid Transfers Distort Incentives and Hurt Growth? Theory and Evidence from 75 Aidrecipient Countries, March 2004

1157 Robert Fenge and Volker Meier, Are Family Allowances and Fertility-related pensions Siamese Twins?, March 2004

1158 Bruno S. Frey, Simon Luechinger, and Alois Stutzer, Valuing Public Goods: The Life Satisfation Approach, March 2004

1159 Jerome L. Stein and Guay C. Lim, Asian Crises: Theory, Evidence, Warning-Signals, March 2004

1160 Romain Ranciere, Aaron Tornell, and Frank Westermann, Crises and Growth: A ReEvaluation, March 2004

1161 Assaf Razin and Efraim Sadka, Transparency, Specialization and FDI, March 2004

1162 Ludger Woessmann, How Equal Are Educational Opportunities? Family Background and Student Achievement in Europe and the United States, March 2004

1163 B.M.S. van Praag and Barbara E. Baarsma, Using Happiness Surveys to Value Intangibles: The Case of Airport Noise, March 2004

1164 Aaron Tornell, Frank Westermann, and Lorenza Martínez, The Positive Link Between Financial Liberalization, Growth, and Crises, March 2004

1165 Helge Berger and Carsten Hefeker, One Country, One Vote? Labor Market Structure and Voting Rights in the ECB, March 2004

1166 Clemens Fuest and Martin Kolmar, A Theory of User-Fee Competition, March 2004

1167 Friedrich Schneider and Robert Klinglmair, Shadow Economies around the World: What Do We Know?, April 2004

1168 Horst Raff and Nicolas Schmitt, Exclusive Dealing and Common Agency in International Markets, April 2004

1169 M. Hashem Pesaran and Allan Timmermann, Real Time Econometrics, April 2004

1170 Sean D. Barrett, Privatisation in Ireland, April 2004

1171 V. Anton Muscatelli, Patrizio Tirelli and Carmine Trecroci, Can Fiscal Policy Help Macroeconomic Stabilisation? Evidence from a New Keynesian Model with Liquidity Constraints, April 2004 
1172 Bernd Huber and Marco Runkel, Tax Competition, Excludable Public Goods and User Charges, April 2004

1173 John McMillan and Pablo Zoido, How to Subvert Democracy: Montesinos in Peru, April 2004

1174 Theo Eicher and Jong Woo Kang, Trade, Foreign Direct Investment or Acquisition: Optimal Entry Modes for Multinationals, April 2004

1175 Chang Woon Nam and Doina Maria Radulescu, Types of Tax Concessions for Attracting Foreign Direct Investment in Free Economic Zones, April 2004

1176 M. Hashem Pesaran and Andreas Pick, Econometric Issues in the Analysis of Contagion, April 2004

1177 Steinar Holden and Fredrik Wulfsberg, Downward Nominal Wage Rigidity in Europe, April 2004

1178 Stefan Lachenmaier and Ludger Woessmann, Does Innovation Cause Exports? Evidence from Exogenous Innovation Impulses and Obstacles, April 2004

1179 Thiess Buettner and Johannes Rincke, Labor Market Effects of Economic Integration The Impact of Re-Unification in German Border Regions, April 2004

1180 Marko Koethenbuerger, Leviathans, Federal Transfers, and the Cartelization Hypothesis, April 2004

1181 Michael Hoel, Tor Iversen, Tore Nilssen, and Jon Vislie, Genetic Testing and Repulsion from Chance, April 2004

1182 Paul De Grauwe and Gunther Schnabl, Exchange Rate Regimes and Macroeconomic Stability in Central and Eastern Europe, April 2004

1183 Arjan M. Lejour and Ruud A. de Mooij, Turkish Delight - Does Turkey's accession to the EU bring economic benefits?, May 2004

1184 Anzelika Zaiceva, Implications of EU Accession for International Migration: An Assessment of Potential Migration Pressure, May 2004

1185 Udo Kreickemeier, Fair Wages and Human Capital Accumulation in a Global Economy, May 2004

1186 Jean-Pierre Ponssard, Rent Dissipation in Repeated Entry Games: Some New Results, May 2004

1187 Pablo Arocena, Privatisation Policy in Spain: Stuck Between Liberalisation and the Protection of Nationals' Interests, May 2004

1188 Günter Knieps, Privatisation of Network Industries in Germany: A Disaggregated Approach, May 2004 
1189 Robert J. Gary-Bobo and Alain Trannoy, Efficient Tuition Fees, Examinations, and Subsidies, May 2004

1190 Saku Aura and Gregory D. Hess, What's in a Name?, May 2004

1191 Sjur Didrik Flåm and Yuri Ermoliev, Investment Uncertainty, and Production Games, May 2004

1192 Yin-Wong Cheung and Jude Yuen, The Suitability of a Greater China Currency Union, May 2004

1193 Inés Macho-Stadler and David Pérez-Castrillo, Optimal Enforcement Policy and Firms' Emissions and Compliance with Environmental Taxes, May 2004

1194 Paul De Grauwe and Marianna Grimaldi, Bubbles and Crashes in a Behavioural Finance Model, May 2004

1195 Michel Berne and Gérard Pogorel, Privatization Experiences in France, May 2004

1196 Andrea Galeotti and José Luis Moraga-González, A Model of Strategic Targeted Advertising, May 2004

1197 Hans Gersbach and Hans Haller, When Inefficiency Begets Efficiency, May 2004

1198 Saku Aura, Estate and Capital Gains Taxation: Efficiency and Political Economy Consideration, May 2004

1199 Sandra Waller and Jakob de Haan, Credibility and Transparency of Central Banks: New Results Based on Ifo's World Economicy Survey, May 2004

1200 Henk C. Kranendonk, Jan Bonenkamp, and Johan P. Verbruggen, A Leading Indicator for the Dutch Economy - Methodological and Empirical Revision of the CPB System, May 2004

1201 Michael Ehrmann, Firm Size and Monetary Policy Transmission - Evidence from German Business Survey Data, May 2004

1202 Thomas A. Knetsch, Evaluating the German Inventory Cycle - Using Data from the Ifo Business Survey, May 2004

1203 Stefan Mittnik and Peter Zadrozny, Forecasting Quarterly German GDP at Monthly Intervals Using Monthly IFO Business Conditions Data, May 2004 